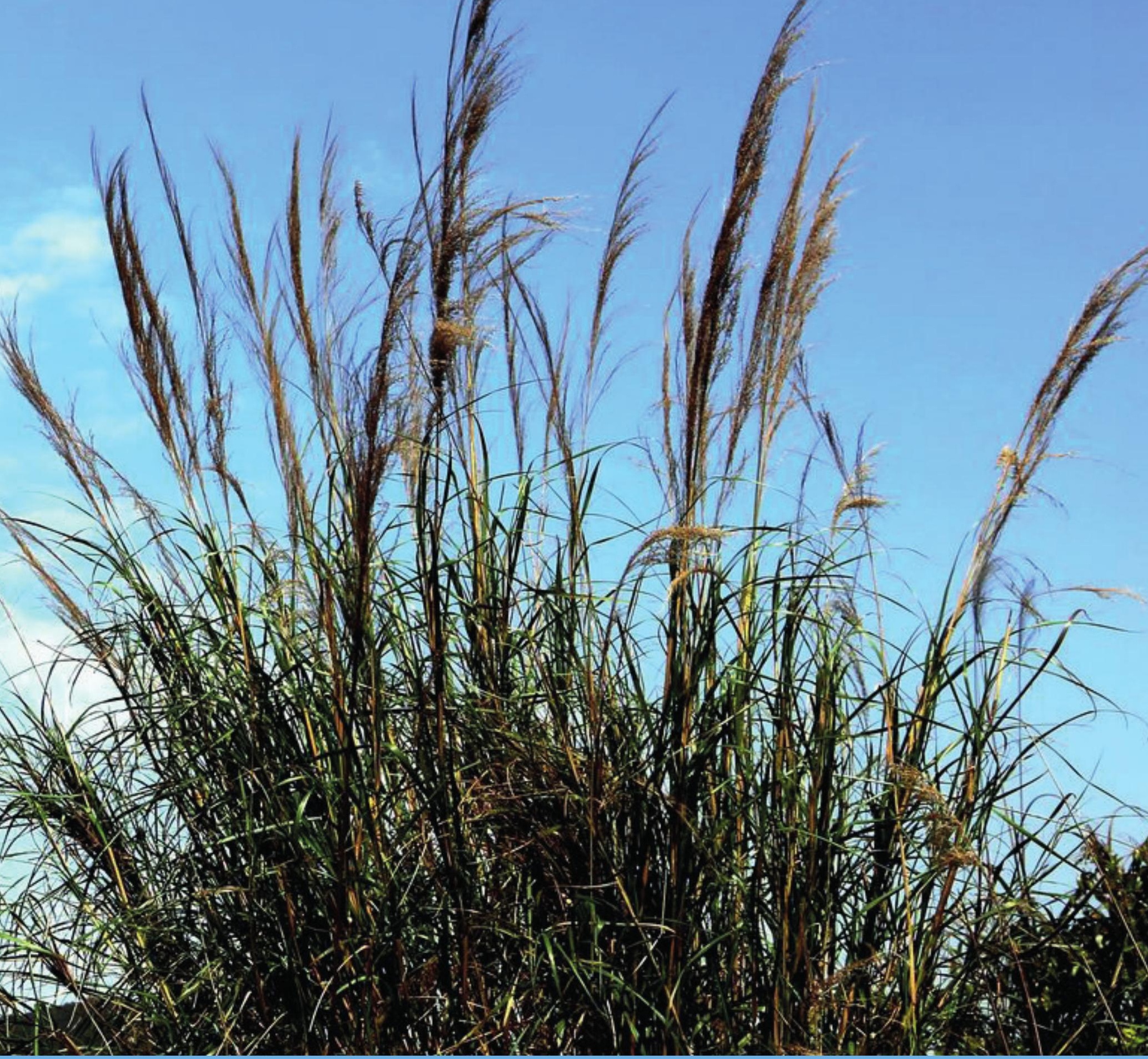

Processing of Miscanthus sinensis to produce sugars or cellulose pulp

Paulien Harmsen, Edwin Keijsers, Brigit Beelen

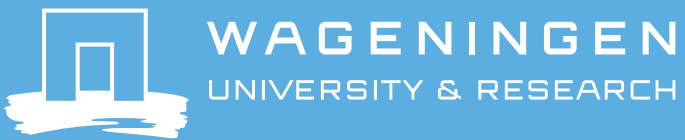





\section{Processing of Miscanthus sinensis to produce sugars or cellulose pulp}

Authors: Paulien Harmsen, Edwin Keijsers, Brigit Beelen

With cooperation of Richard Op den Kamp, Mario van Wandelen, Jeroen van Bon

This research project has been carried out by Wageningen Food \& Biobased Research commissioned by the Dutch Ministry of Agriculture, Nature and Food Quality (project number 6224066200). 
Version: final

Reviewer: Johan van Groenestijn

Approved by: Jan Jetten

Client: the Dutch Ministry of Agriculture, Nature and Food Quality

This report can be downloaded for free at https://doi.org/10.18174/527985 or at www.wur.eu/wfbr (under publications)

(C) 2020 Wageningen Food \& Biobased Research, institute within the legal entity Stichting Wageningen Research.

PO box 17, 6700 AA Wageningen, The Netherlands, T + 31 (0)317 4800 84, E info.wfbr@wur.nl, www.wur.eu/wfbr. Wageningen Food \& Biobased Research is part of Wageningen University \& Research.

All rights reserved. No part of this publication may be reproduced, stored in a retrieval system of any nature, or transmitted, in any form or by any means, electronic, mechanical, photocopying, recording or otherwise, without the prior permission of the publisher. The publisher does not accept any liability for inaccuracies in this report. 


\section{Summary}

Eight genotypes of Miscanthus sinensis were provided by WPR with differences in composition and digestibility. The eight genotypes showed significant differences in chemical composition. A correlation between glucose and lignin content and digestibility could be present.

\section{Fermentable sugars}

The 8 genotypes were subjected to a two-stage process to produce fermentable sugars. The first stage consisted of an acid treatment at elevated pressure and temperature, the second stage of an enzymatic hydrolysis. Clear differences in the amount of fermentable sugars obtained were found. The genotype with the highest digestibility (074, lowest amount of cellulose and lignin) also resulted in the highest amount of fermentable sugars. Correlation between the digestibility and fermentable sugar yield of the other genotypes was less clear.

Two genotypes (017 and 074) were also subjected to three other pulping processes as first stage (acid super heated steam (SHS), alkaline SHS and alkaline pulping at $120^{\circ} \mathrm{C}$ ), followed by a second stage of enzymatic hydrolysis. Similar results were obtained: the genotype with the highest digestibility (074, lowest amount of cellulose and lignin) also resulted in the highest amount of glucose. Release of xylose was similar. Overall, glucose release was limited, xylose release was moderate for the alkaline treated pulps.

\section{Cellulose pulp}

Another part of the study was the conversion of two genotypes (017 and 074) to cellulose pulp by four different methods: prehydrolysis followed by organosolv, acid super heated steam (SHS, alkaline SHS and alkaline pulping at $120^{\circ} \mathrm{C}$. The cellulose pulps were used to make hand sheets.

The glucose content (cellulose) after treatment was increased from 38\% to $60 \%$ for Miscanthus 017 and from $30 \%$ to $59 \%$ for Miscanthus 074 . After acid and SHS treatment still a high percentage of lignin (AIL) was present in the product. After alkaline treatment a high amount of xylose (hemicellulose) was still present.

For the production of a cellulose pulp, the alkaline 50L treatment of both Miscanthus genotypes was most promising as this treatment resulted in samples with the highest cellulose content, around 60 wt\%. However, more purification steps are required to obtain a pure cellulose product. Based on the composition of the starting material Miscanthus 017 is more interesting due to a higher initial cellulose content.

\section{Hand sheets}

The fibre properties of cellulose pulps and the mechanical- and physical properties of hand sheets were analysed. The cellulose-enriched samples were disintegrated, mechanically beaten and handsheets were prepared. The properties of these handsheets were determined to provide insight in the morphology of the pulps after chemical treatment, and on the performance for application in paper products.

Results showed that the acid-SHS treatment was less effective in breaking down the fibre bundles of the Miscanthus biomass into fibres compared to the alkaline treatments. The acid treated cellulose pulp was not fully disintegrated into fibres, resulting in a high bulk value. Also, the bulk levels of the alkaline treated pulps were at the higher side of chemical wood pulps, showing that the pulping treatments applied in this study were less severe than chemical pulping treatments of commercial pulps. Results showed that bulk was lower for Miscanthus 074 than for 017, indicating that upon pulping 074 is broken down into fibres more easily than 017.

The paper properties showed that opening of the fibre structure of Miscanthus was most effective for the alkaline benchmark process. The SHS treatments did not succeed in breaking all fibre bundles into single fibres. Results corresponded with the observation that both alkaline pulping stages were not severe enough to produce a chemical unbleached pulp. The acidic SHS process only removed the 
hemicellulose from the lignocellulosic structure. The resulting pulp showed very poor paper forming properties. Overall, paper properties of the two Miscanthus samples were similar. Larger differences were observed between the various pulping processes.

Mechanical strength of the papers produced after beating in a valley beater showed that the alkaline pulps did not show the quality of chemical unbleached pulps. The properties were comparable to (chemi-) mechanical pulps. The mechanical properties of the acid SHS pulp were at the lower end of mechanical pulp properties.

\section{Value of cellulose pulps from Miscanthus}

The combination of acid soaking with superheated steam resulted in an almost complete removal of the hemicellulose fraction (xylose), with a cellulose/lignin enriched fraction as solid residue. This solid residue might be a suitable material for the production a dissolving cellulose pulp, as only the lignin fraction needs to be removed. Prerequisite for this is a high degree of polymerisation (DP) of the cellulose. Some indications were found that the degree of polymerisation of the cellulose fraction was sharply decreased (which is often the case for acid processes), making the application as dissolving cellulose less prevalent. In addition, the extracted hemicellulose (xylose) from Miscanthus might be used as raw material for chemical modifications to e.g. xylitol, but for that an analysis is required of the liquid fraction. Due to the severity of the process, it is also possible that xylose is further converted to furfural or (volatile) organic acids and that milder conditions are also an option.

The use of the superheated steam process in combination with an alkaline or acidic soaking does not result in fibres with properties comparable to unbleached chemical pulps. The properties of the pulp resulting from the alkaline superheated steam process were comparable with chemi-mechanical pulps. Some reduction of the amount of alkali used may result in a relatively cheap process to produce chemi-mechanical pulps from Miscanthus. 


\section{Contents}

$\begin{array}{ll}\text { Summary } & 3\end{array}$

$\begin{array}{llr}1 & \text { Introduction } & 7\end{array}$

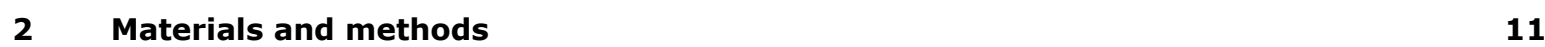

2.1 Materials 11

2.2 Pretreatment methods $\quad 11$

2.2.1 Acid hydrolysis and enzymatic hydrolysis $\quad 11$

2.2.2 Prehydrolysis with water and organosolv pulping 12

2.2.3 Superheated steam with acid pre-treatment (acid SHS) 12

2.2.4 Alkaline soaking and superheated steam treatment (alkaline SHS) 12

2.2.5 Alkaline pulping in 50L conical screw reactor (alkaline 50L) 13

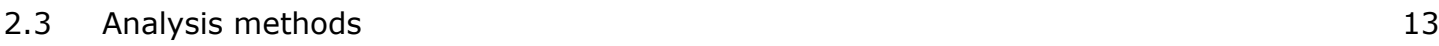

2.3.1 Chemical composition Miscanthus samples 13

2.3.2 Enzymatic kits for glucose and xylose 14

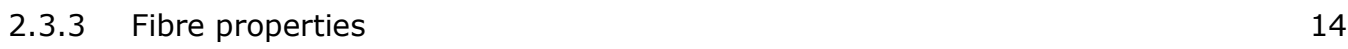

$3 \quad$ Results and discussion $\quad 15$

3.1 Chemical composition of starting materials 15

3.2 Cellulose pulp from Miscanthus 16

3.2.1 Introduction $\quad 16$

3.2.2 $\mathrm{pH}$ during treatment 16

$\begin{array}{lll}3.2 .3 & \text { Pulping yield } & 17\end{array}$

3.2.4 Chemical composition after treatment 18

$\begin{array}{ll}3.2 .5 & \text { Mass balances }\end{array}$

3.2.6 Fibre properties of cellulose pulps $\quad 22$

3.2.7 Mechanical properties of hand sheets $\quad 23$

$\begin{array}{lll}3.2 .8 & \text { Physical properties of hand sheets } & 23\end{array}$

$\begin{array}{lll}3.3 & \text { Fermentable sugars from Miscanthus } & 26\end{array}$

3.3.1 Introduction $\quad 26$

3.3.2 Acid treatment with coarse particles $\quad 26$

3.3.3 Reduction of particle size and increasing intensity acid hydrolysis $\quad 27$

3.3.4 Enzymatic hydrolysis of cellulose pulps 28

3.3.5 Comparison between acid hydrolysis, superheated steam treatments and alkaline pulping. $\quad 31$

4 Conclusions and recommendations $\quad 33$

$\begin{array}{lll}\text { Annex } 1 & \text { Physical properties of the hand sheets }\end{array}$ 


\section{Introduction}

Wageningen UR investment program Development of Resource use efficient chains (RUE) was funded by the Dutch Ministry of Economic affairs. Efficient use of biomass was one of the topics, and in this project the use of Miscanthus as biomass source to produce sugars and cellulose pulp for the production of paper was investigated.

Two main research questions were studied:

- Is there a difference in suitability of Miscanthus sinensis genotypes for the production of fermentable sugars and cellulose pulp?

- Which process is most suited to process the Miscanthus sinensis genotypes into fermentable sugars and cellulose pulp?

Eight different Miscanthus sinensis genotypes were kindly provided by Wageningen Plant Research (WPR) of WUR. These genotypes were selected because of their different feed digestibility characteristics as a feed, determined by WPR (Table 1). All eight genotypes were tested on their suitability as resource to produce fermentable sugars. An acid-based two stage process was applied as shown in Figure 1.

Table 1 Miscanthus sinensis genotypes and their digestibility (data provided by WPR).

\begin{tabular}{cc} 
Genotype & Digestibility \\
OD1302-074 & Excellent \\
\hline OD1302-106 & Excellent \\
\hline OD1302-073 & Excellent \\
\hline OD1302-082 & Excellent \\
\hline OD1302-036 & Good \\
\hline OD1302-117 & Good \\
\hline OD1302-066 & Average \\
\hline OD1302-017 & Poor \\
\hline
\end{tabular}

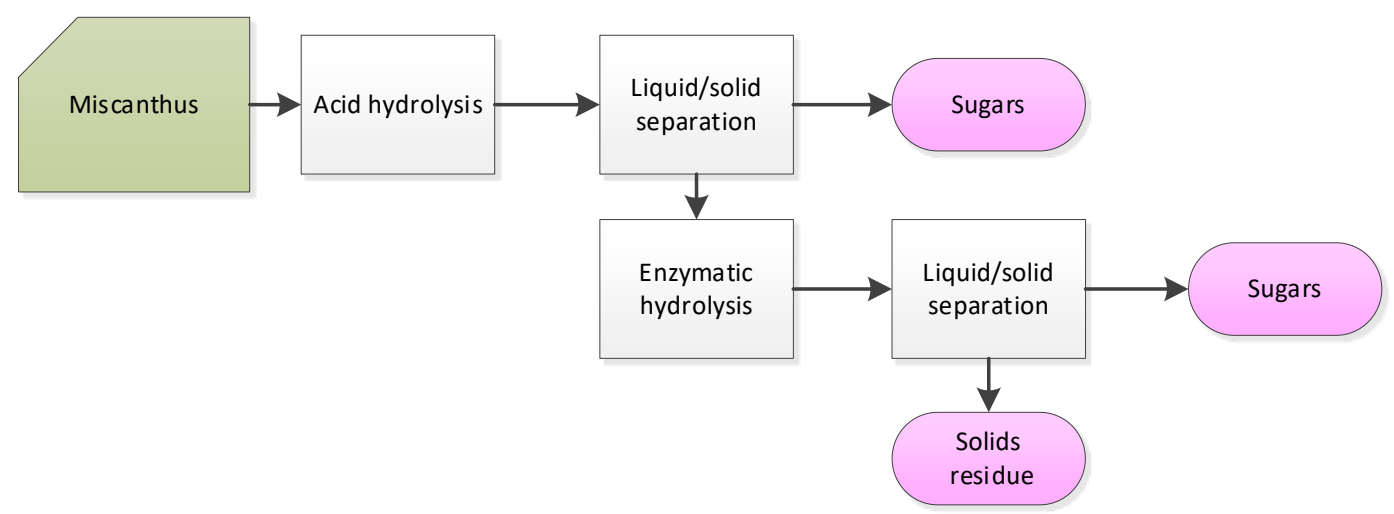

Figure 1 Consecutive acid and enzymatic hydrolysis process to produce sugars

In addition, four other pulping or pretreatment processes were tested (see Figure 2) on two selected genotypes (the two extremes OD1302-074 and OD1302-017) with a dual objective:

- To apply as pretreatment prior to enzymatic hydrolysis to establish the amount of fermentable sugars that could be produced, with the above-mentioned acid hydrolysis as base case.

- To evaluate the four pretreatment processes as the first stage in a process to produce cellulose pulp, an intermediate product to produce dissolving cellulose. The whole process to dissolving cellulose pulp consists of several steps, including bleaching stages following these first pulping stages. In this study, only the first stage was evaluated, i.e. the extraction of a crude cellulose fraction from biomass by pulping. 


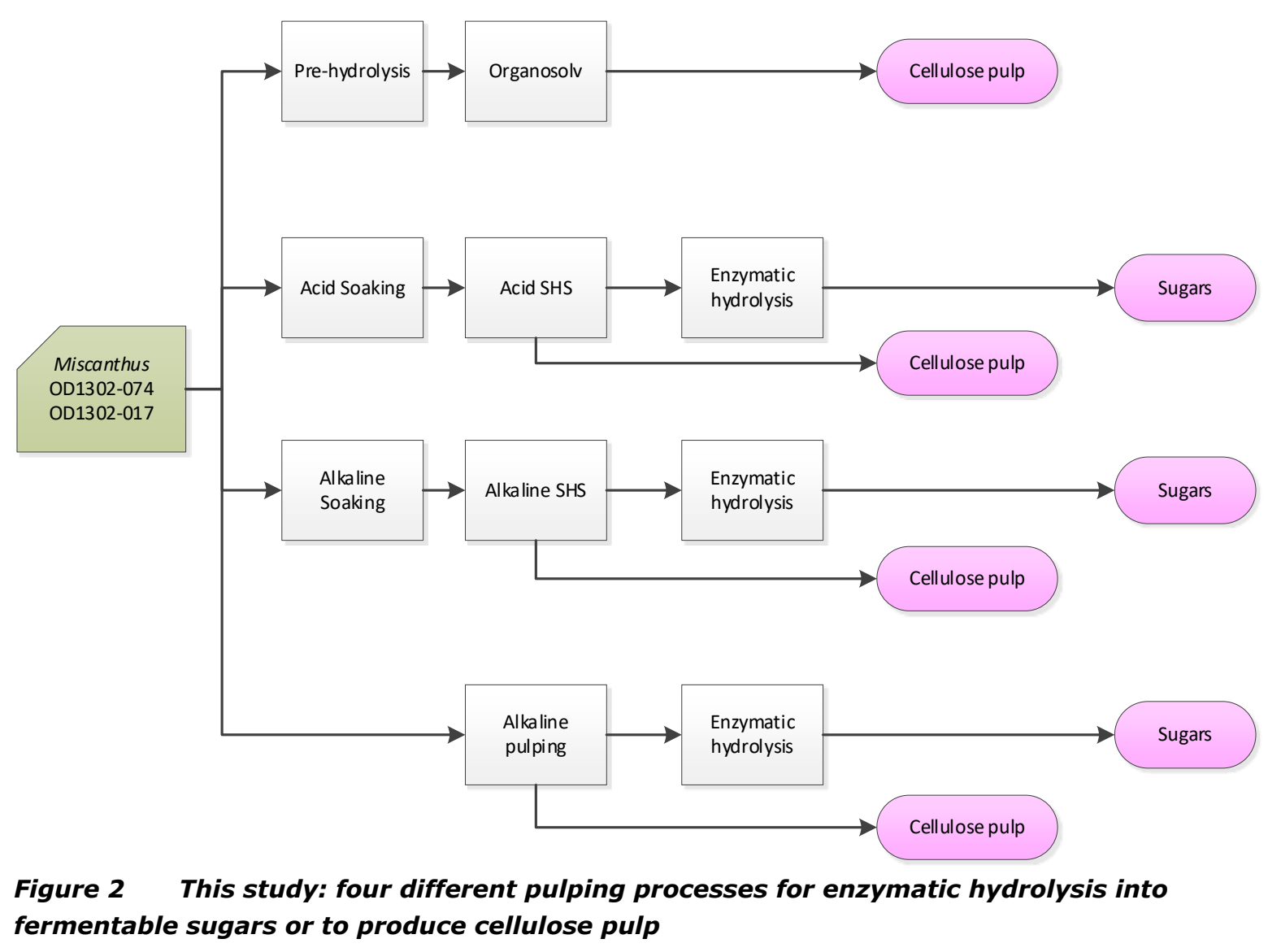

Rationale behind this is to study the different modes of action of these four pulping processes. The first and fourth process in Figure 2 are very suitable to produce dissolving cellulose as lignin is (partly) dissolved in the liquid phase and molecular weight of cellulose remains intact. Dissolving cellulose pulp (cellulose pulp with a high purity and high molecular weight) has a good market value. Once dissolved it can be spun into fibres for textile (e.g. viscose) or chemically modified to thermoplastic celluloses (like cellulose acetate) with an even higher market value. Currently, wood and cotton are the main sources for dissolving pulp. Energy demanding- and sulphur containing pulping processes are applied, and in most cases, chlorine is used in purification steps for delignification of the pulp. Additional purification steps like bleaching or washing are needed to obtain a pulp with desired properties. The second and third process are more suitable to produce (fermentable) sugars. Here the sugars are dissolved in the liquid phase and lignin is discarded as a solid residue.

Figure 3 shows the role of $\mathrm{pH}$ in pretreatment processes in relation to changes in chemical composition of the lignocellulosic matrix. As a rule of thumb, one can say that at lower $\mathrm{pH}$ the hemicellulose fraction is dissolved leaving a solid fraction enriched in lignin and cellulose. On the other hand, under alkaline conditions or high pH more of the lignin fraction is dissolved, leaving a solid residue enriched in cellulose and hemicellulose. 


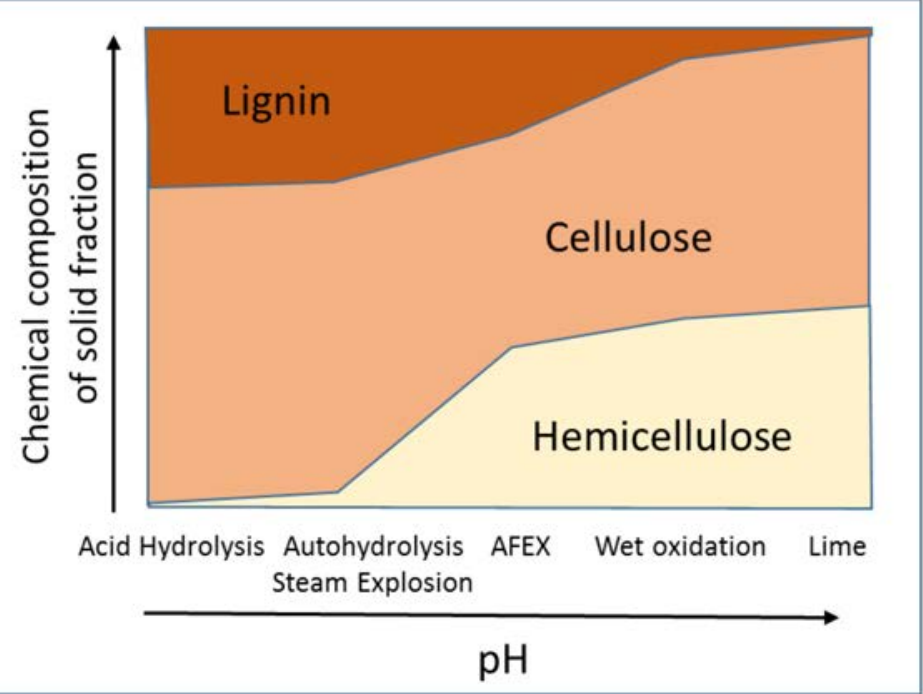

Figure 3 Changes in chemical composition of the solid fraction after pretreatment and relation to pH (Adapted from Carvalheiro et al (2008) Journal of Scientific and Industrial Research 67(11): 849-864))

In chapter 2 the materials and methods are described, and in chapter 3 the results production of cellulose pulp and hand sheets, and subsequently the enzymatic hydrolysis of all samples to monomeric sugars. This report is finalized with overall conclusions and recommendations in chapter 4 . 


\section{Materials and methods}

\subsection{Materials}

- $\quad$ Eight different Miscanthus genotypes were supplied by WPR. Digestibility varied from poor to excellent. Two samples are illustrated in Figure 4.

- $\quad$ For the enzymatic treatment, Ctec 2 from Sigma Aldrich was used. To prevent bacterial growth Pen Strep originating from Penicillin Streptomycin was used, obtained by Sigma Aldrich.

- $\quad$ Other chemicals were obtained from VWR, Merck or Sigma.
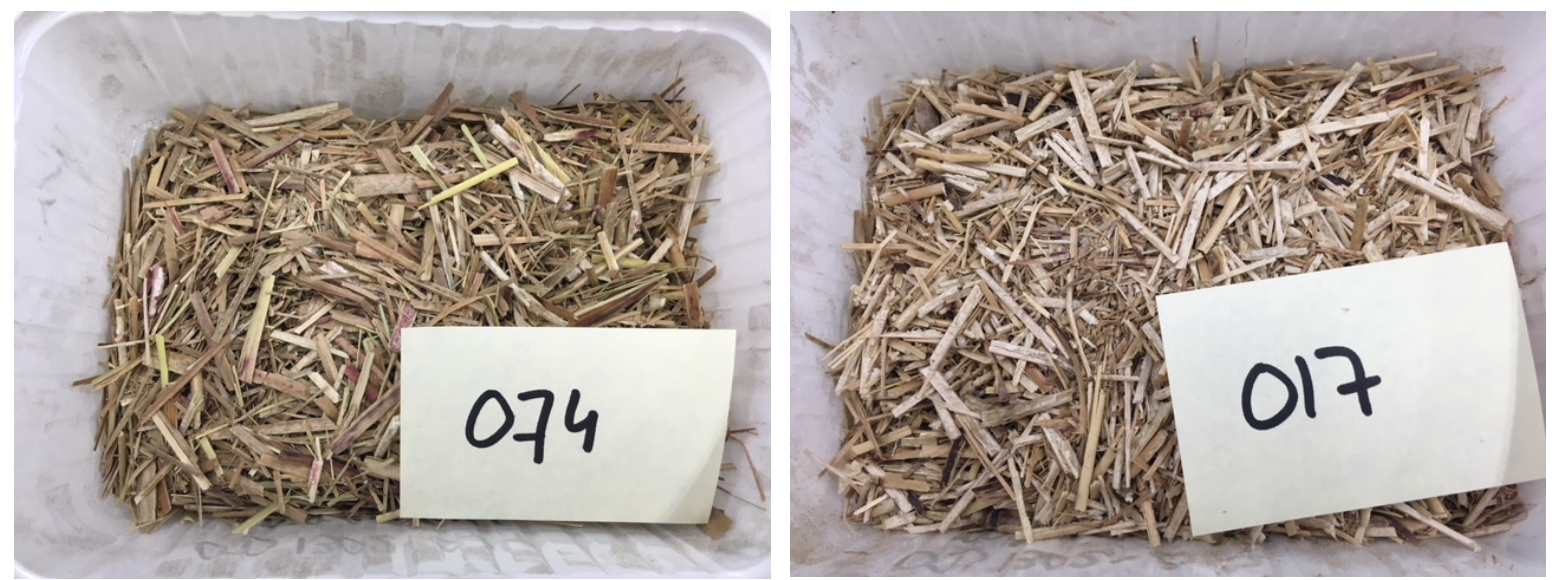

Figure 4 Miscanthus 074 ("excellent") and Miscanthus 017 ("poor") after cutting

\subsection{Pretreatment methods}

\subsubsection{Acid hydrolysis and enzymatic hydrolysis}

Miscanthus was treated with sulphuric acid at $160^{\circ} \mathrm{C} .4 .5 \mathrm{w} / \mathrm{w} / \%$ biomass was dispersed in water in a stainless steel $100 \mathrm{~mL}$ reaction vessel. $2.2 \mathrm{w} / \mathrm{w} \% \mathrm{H}_{2} \mathrm{SO}_{4}$ on dry biomass was used to lower the $\mathrm{pH}$ between 1.5 and 2.0. The reaction was performed for 30 minutes at $160^{\circ} \mathrm{C}$ without stirring. Heating was applied by submerging the reaction vessels in a preheated silicon oil bath. The temperature was measured using a thermocouple and Piotech data recorder Acid treatment started as the desired temperature in the reaction vessel had been achieved. After cooling the solid fraction and the liquid fraction 1 were separated using a tea sieve.

For the enzymatic hydrolysis a $5 \mathrm{w} / \mathrm{w} \%$ dispersion in water was prepared in a closed vessel of $250 \mathrm{~mL}$. The $\mathrm{pH}$ was adjusted to $\mathrm{pH} 5$ with $2 \mathrm{~N} \mathrm{NaOH}$. The solution was stirred and heated up to $55^{\circ} \mathrm{C}$ in a water bath. A dose of $0.02 \mathrm{~mL} / \mathrm{g}$ dry biomass antibiotic Pen Strep (Penicillin Streptomycin) was added to prevent the hydrolysis mixture from undesired microbial conversion. The enzyme CTec2 $(5 \% \mathrm{w} / \mathrm{w})$ was added to start the reaction. After 24 and 72 hours the enzyme was inactivated at $90^{\circ} \mathrm{C}$ for 10 minutes. After cooling remaining solids were separated from the hydrolysis liquid by centrifugation (15 minutes, $15000 \mathrm{~g}, 15^{\circ} \mathrm{C}$ ). The processing scheme is given in Figure 5. 


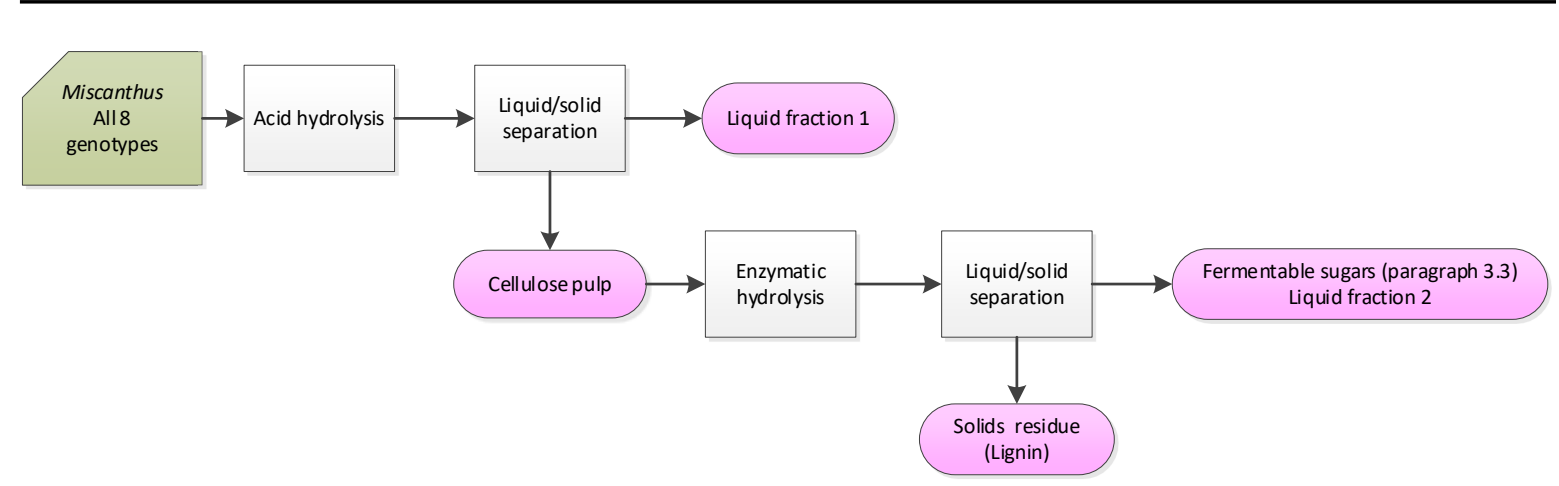

Figure $5 \quad$ Acid hydrolysis followed by enzymatic hydrolysis to produce sugars

\subsubsection{Prehydrolysis with water and organosolv pulping}

Miscanthus was first prehydrolysed (autohydrolysed) for 60 minutes at $170^{\circ} \mathrm{C}$. Thereafter an organosolv process took place with $80 \%$ acetic acid as organic solvent at $170^{\circ} \mathrm{C}$ for 90 minutes. The samples were washed three times with acetic acid to remove solubilized lignin and three times with water, filtered and dried in the fume hood.

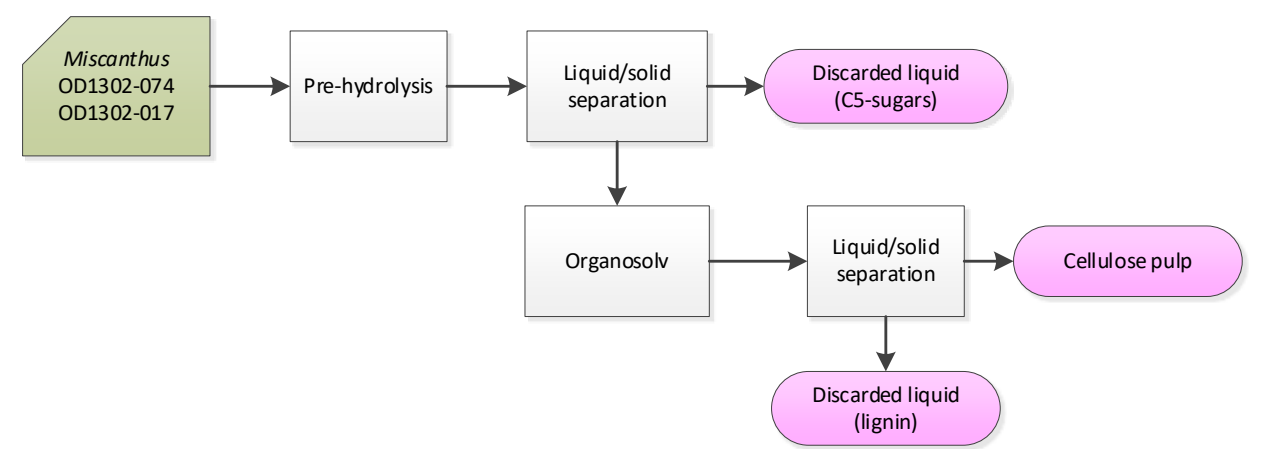

Figure 6 Prehydrolysis followed by organosolv pulping

\subsubsection{Superheated steam with acid pre-treatment (acid SHS)}

$1 \mathrm{~kg}$ of dry material was soaked (overnight) in $2 \% \mathrm{H}_{2} \mathrm{SO}_{4}$ solution, with a solid to liquid ratio of $1: 10$. After draining over a cheese cloth the material was treated in the SHS reactor for 10 minutes at $160^{\circ} \mathrm{C}$ and 6 bar. The solid material was washed 4-5 times with water and solids were separated from the liquid with a cheese cloth. For analysis purposes, the material was stored in the freezer at $-20^{\circ} \mathrm{C}$.

Enzymatic hydrolysis was done as described in paragraph 2.2.1

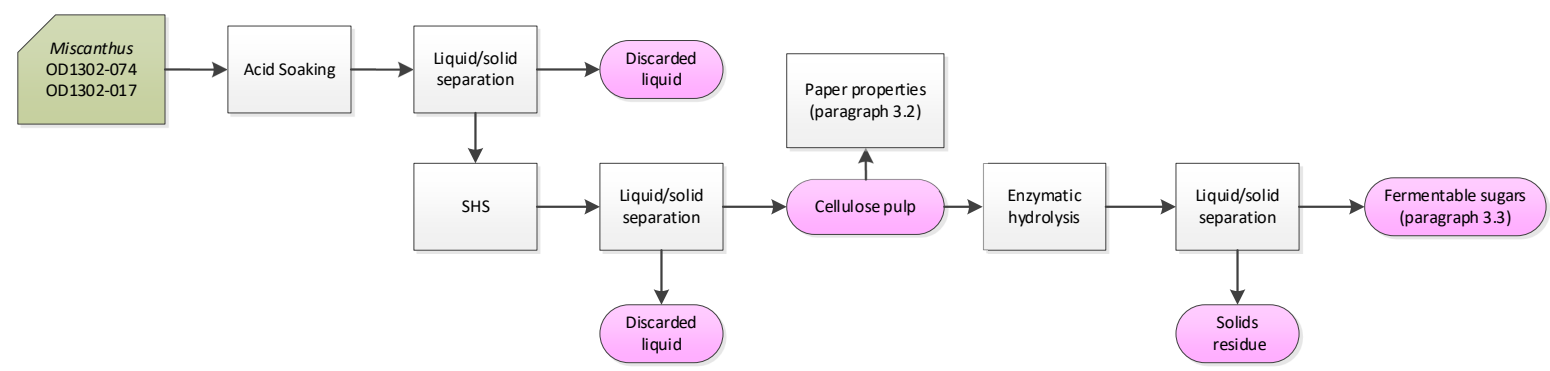

Figure $7 \quad$ Acid soaking followed by superheated steam (SHS) treatment

\subsubsection{Alkaline soaking and superheated steam treatment (alkaline SHS)}

$1 \mathrm{~kg}$ of dry material was soaked (overnight) in water with $15 \% \mathrm{NaOH}$ based on the dry material, with a solid to liquid ratio of $1: 10$. After draining over a cheese cloth the material was treated in the SHS reactor for 10 minutes at $160^{\circ} \mathrm{C}$ and 6 bar. The solid material was washed $4-5$ times with water and 
solids were separated from the liquid phase by a cheese cloth. For analysis purposes, the material was stored in the freezer at $-20^{\circ} \mathrm{C}$.

Enzymatic hydrolysis was done as described in paragraph 2.2.1.

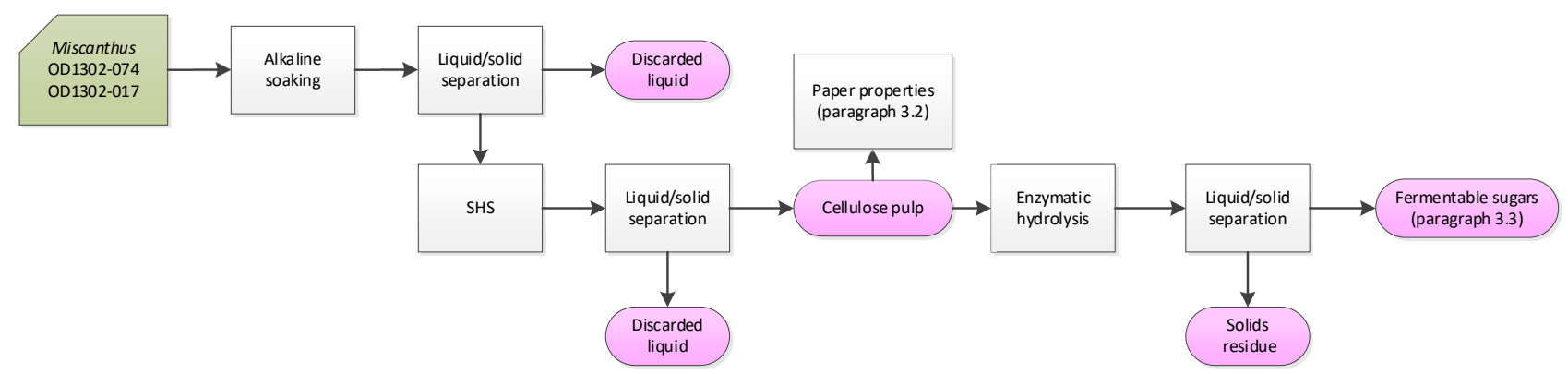

Figure $8 \quad$ Alkaline soaking followed by superheated steam (SHS) treatment

\subsubsection{Alkaline pulping in $50 \mathrm{~L}$ conical screw reactor (alkaline $50 \mathrm{~L}$ )}

An alkaline extraction in a conical $50 \mathrm{~L}$ reactor was performed on the genotypes 17 and 74 .

Approximately $1-2 \mathrm{~kg}$ of dry material was placed into the $50 \mathrm{~L}$ reactor. Water was added in the solid to liquid ratio of $1: 10$ and $15 \% \mathrm{NaOH}$ based on the dry matter was added to the mixture. The extraction was carried out for $90 \mathrm{~min}$. at $120^{\circ} \mathrm{C}$.

After the extraction, the mixture was poured over a cheese cloth to separate the liquid fraction. The solid material was washed for 5-6 times with water and again, separated with cheese cloth. For analysis purposes, the material was stored in the freezer at $-20^{\circ} \mathrm{C}$.

Enzymatic hydrolysis was done as described in paragraph 2.2.1

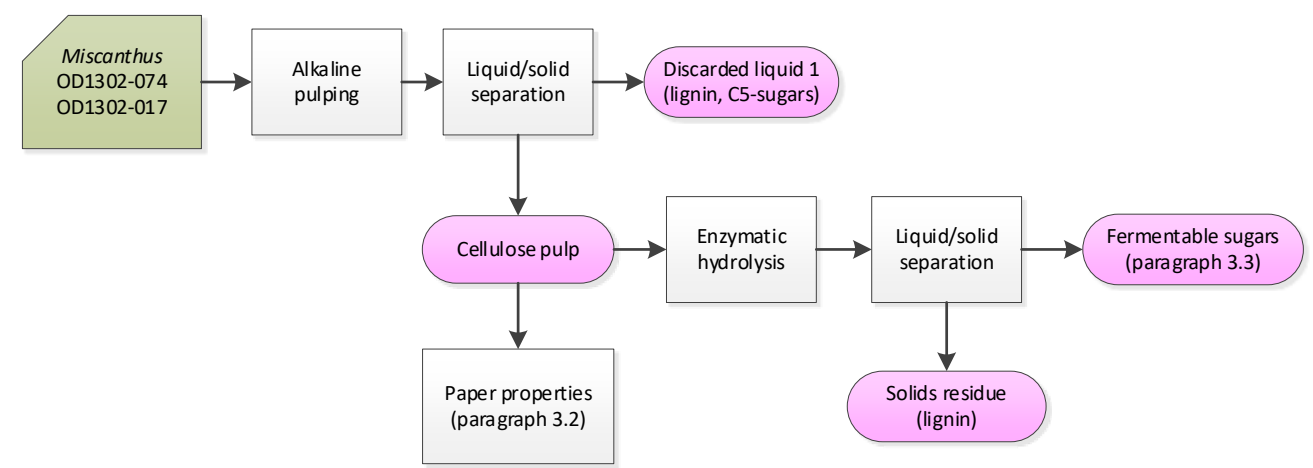

Figure 9 Alkaline pulping in conical screw reactor.

\subsection{Analysis methods}

\subsubsection{Chemical composition Miscanthus samples}

Sample material was dried at $50^{\circ} \mathrm{C}$ and milled. The samples were hydrolysed with sulphuric acid (12M 1 hour at $30^{\circ} \mathrm{C}, 1 \mathrm{~N} 3$ hours at $100^{\circ} \mathrm{C}$ ). The formed monosaccharides in the hydrolysate were quantified by HPAEC (Dionex Corporation, California, USA). The acid insoluble lignin was determined gravimetrically after washing and the acid soluble lignin in the hydrolysate was determined spectrophotometrically at $205 \mathrm{~nm}$ (TAPPI UM 250). Uronic acids in the hydrolysate were also determined spectrophotometrically according to the method described by Blumenkrantz. 


\subsubsection{Enzymatic kits for glucose and xylose}

Enzymatic kits of Megazyme were used to determine the concentration of glucose and xylose in the liquids after enzymatic hydrolysis:

- The D-Glucose kit is a UV-method (measurement at $340 \mathrm{~nm}$ ) for the determination of D-glucose in foodstuffs, beverages and other materials

- The D-Xylose kit is a UV-method (measurement at $340 \mathrm{~nm}$ ) for the determination of D-xylose in fermentation broths and hydrolysates of plant material and polysaccharides.

\subsubsection{Fibre properties}

The wet cellulose pulp was disintegrated using a valley beater according to ISO 5264/1. Instead of 360 grams, an equivalent of 200 grams of oven-dried pulp was used. After disintegration a small sample was taken and the beating degree was measured according to ISO 5267-1 using the Schopper Riegler apparatus. Subsequently laboratory beating of the pulp in the valley beater was performed to obtain a sample of about 30 and about $50 \mathrm{SR}$ beating degree. Beating degree as function of beating time was recorded.

Pulp samples taken at 30 and 50 SR beating degree were used to produce hand sheets according to ISO 5269/2 using the Rapid-Köthen sheet former. After conditioning for over 24 hours the mechanical properties of the sheets were measured: grammage (ISO 536), thickness (single sheet) and bulk (ISO 534), tensile properties (ISO 1924-2), tearing resistance (ISO 1974), SCT index (ISO 9895), air-permeance (ISO 5636) and roughness (ISO 8791). 


\section{Results and discussion}

\subsection{Chemical composition of starting materials}

Homogeneous samples of Miscanthus for analysis purposes were prepared by milling the biomass to a fine powder, and these samples were used to determine the chemical composition.

The results of the chemical composition of all 8 Miscanthus samples are shown in Table 2. The variation in the composition was significant. The cellulose content (expressed as glucose) varied from $29.8-38.7 \%$ and the xylose content from $17.4-21.6 \%$. Also, the lignin content varied slightly.

Table 2 Chemical composition of the Miscanthus starting materials.

\begin{tabular}{|c|c|c|c|c|c|c|c|c|c|c|c|c|c|}
\hline & \multicolumn{3}{|c|}{ Extractives } & \multicolumn{7}{|c|}{ Average polysaccharide contents } & \multicolumn{2}{|c|}{ Lignin } & \multirow{2}{*}{$\begin{array}{r}\text { Total } \\
(\%)\end{array}$} \\
\hline & $\begin{array}{c}\text { ethanol/ } \\
\text { toluene } \\
(\%)\end{array}$ & $\begin{array}{c}\text { ethanol } \\
(\%)\end{array}$ & $\begin{array}{c}\text { water } \\
(\%)\end{array}$ & $\begin{array}{c}\text { Arabinose } \\
(\%)\end{array}$ & $\begin{array}{c}\text { Xylose } \\
(\%)\end{array}$ & $\begin{array}{c}\text { Mannose } \\
(\%)\end{array}$ & $\begin{array}{c}\text { Galactose } \\
(\%)\end{array}$ & $\begin{array}{c}\text { Glucose } \\
(\%)\end{array}$ & $\begin{array}{c}\text { Rhamnose } \\
(\%)\end{array}$ & $\begin{array}{c}\text { Uronic } \\
\text { acids } \\
(\%) \\
\end{array}$ & $\begin{array}{l}\text { AIL } \\
(\%)\end{array}$ & $\begin{array}{r}\text { ASL } \\
(\%)\end{array}$ & \\
\hline OD1302-074 (excellent) & 4.50 & 0.50 & 5.20 & 2.40 & 18.30 & 0.10 & 0.60 & 29.80 & 0.00 & 3.00 & 16.40 & 1.00 & 82.70 \\
\hline OD1302-106 (excellent) & 1.90 & 0.50 & 2.80 & 2.10 & 20.30 & 0.00 & 0.50 & 33.50 & 0.00 & 3.00 & 17.30 & 0.90 & 82.90 \\
\hline OD1302-073 (excellent) & 5.00 & 1.70 & 5.90 & 2.20 & 17.40 & 0.10 & 0.60 & 32.50 & 0.00 & 2.40 & 18.90 & 1.10 & 87.80 \\
\hline OD1302-082 (excellent) & 2.90 & 0.90 & 3.70 & 1.80 & 19.90 & 0.00 & 0.40 & 32.10 & 0.00 & 3.30 & 17.30 & 0.80 & 83.20 \\
\hline OD1302-036 (good) & 2.20 & 0.60 & 3.20 & 0.00 & 20.00 & 0.10 & 0.40 & 38.70 & 0.00 & 2.40 & 17.80 & 0.90 & 88.30 \\
\hline OD1302-117 (good) & 3.70 & 1.40 & 2.60 & 2.30 & 19.20 & 0.00 & 0.60 & 32.90 & 0.00 & 3.40 & 18.30 & 0.90 & 85.30 \\
\hline OD1302-066 (average) & 1.80 & 0.50 & 2.40 & 1.80 & 21.60 & 0.00 & 0.40 & 37.60 & 0.00 & 2.30 & 20.10 & 0.60 & 89.30 \\
\hline OD1302-017 (poor) & 2.40 & 0.50 & 3.00 & 1.90 & 19.60 & 0.10 & 0.50 & 38.10 & 0.00 & 2.20 & 19.80 & 0.90 & 89.00 \\
\hline
\end{tabular}

In Figure 10 the extractives, glucose, xylose and lignin content is shown in relation to digestibility. In theory the digestibility might be related to lignin content. OD1302-074 is excellent digestible and has a low lignin content (16.4\%) whereas OD1302-017 is poor digestible and has a high lignin content $(19.8 \%)$.

The figure shows that the digestibility is also related to glucose content, and that there seems to be a close correlation between lignin and glucose content. A low lignin content is coupled to a low glucose content, and a high lignin content to a high glucose content.

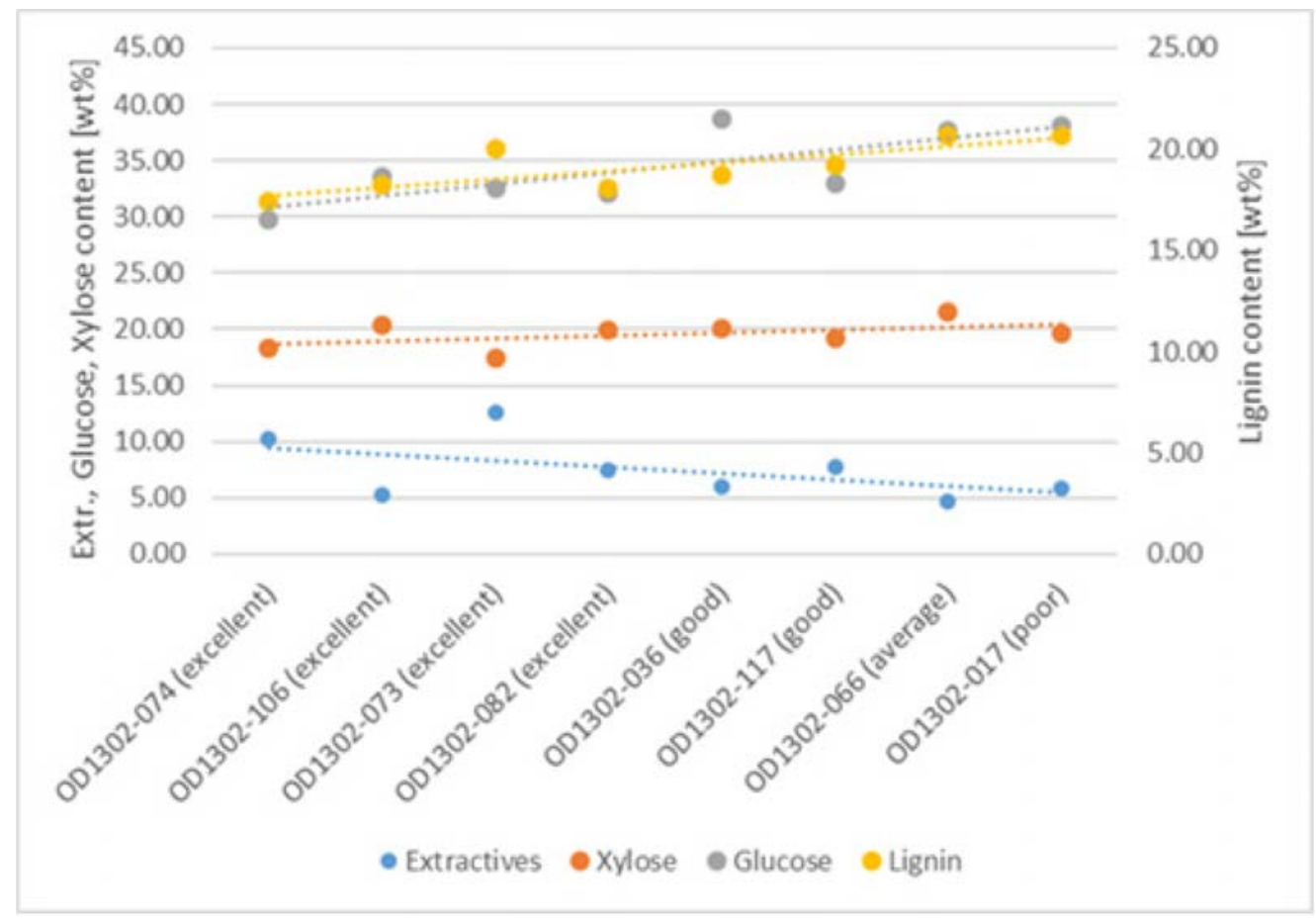

Figure 10 Composition related to digestibility 


\subsection{Cellulose pulp from Miscanthus}

\subsubsection{Introduction}

Aim of this part of the study was to produce a cellulose pulp from Miscanthus samples by four different pulping processes. The plants used were Miscanthus 074 which is excellent digestible and Miscanthus 017 which is poor digestible. The following treatments were applied:

1. Pre-hydrolysis at $170^{\circ} \mathrm{C}$, followed by an organosolv treatment with $80 \%$ acetic acid at $170^{\circ} \mathrm{C}$ (organosolv)

2. Acid soaking and SHS (acid SHS)

3. Alkaline soaking and SHS (alkaline SHS)

4. Alkaline pulping for 90 minutes at $120^{\circ} \mathrm{C}$ (Alkaline $50 \mathrm{~L}$ )

The first experiment was based on the WFBR-patent EP2556190 A1 entitled "Acetic acid based refining process of biomass". The process is a combination of a pre-hydrolysis step in water at high temperature $\left(150-170^{\circ} \mathrm{C}\right)$, followed by a hydrolysis with $80 \%$ acetic acid at $170{ }^{\circ} \mathrm{C}$ for 90 minutes. The second treatment and third treatment included a treatment with the superheated steam equipment at TNO in Zeist (Figure 11, left picture). Before the SHS treatment, the material was soaked overnight in acid or alkaline solutions.

The last treatment was an alkaline treatment for 90 minutes at a temperature of $120^{\circ} \mathrm{C}$ in a $50 \mathrm{~L}$ stirred reactor (Figure 11, right picture).

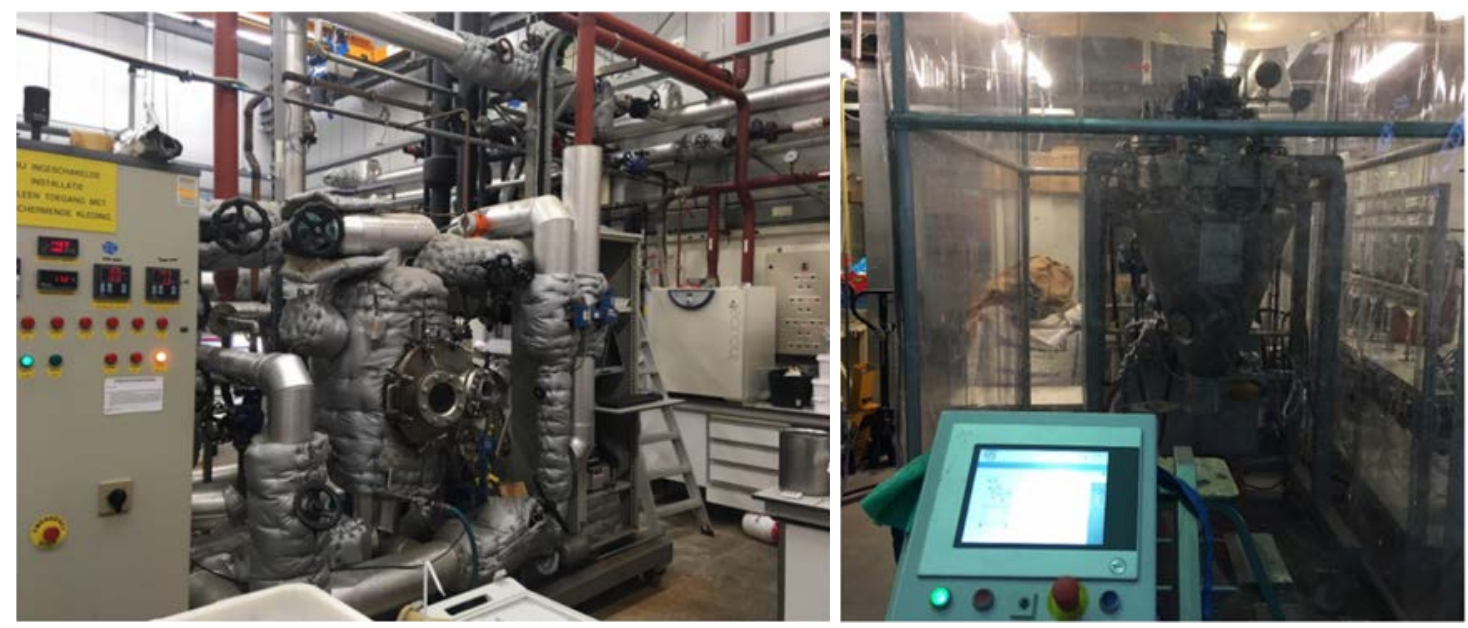

Figure 11 SHS equipment (left picture) and conical screw reactor used for alkaline pulping (right picture)

\subsection{2 $\mathrm{pH}$ during treatment}

The $\mathrm{pH}$ of the liquid phases was determined during processing (Table 3). Large differences were observed, even after washing of the samples.

Table $3 \quad p H$ of the liquid phases and the washed pulp.

\begin{tabular}{|c|c|c|c|c|}
\hline Sample & & pH during soaking & $\begin{array}{l}\text { pH after } \\
\text { treatment }\end{array}$ & pH after washing \\
\hline \multirow[t]{4}{*}{ Miscanthus 17} & Organosolv & n.d. & n.d. & n.d. \\
\hline & Acid SHS & 1.2 & 2.1 & 3.6 \\
\hline & Alkaline SHS & 12.6 & 10.4 & 9.1 \\
\hline & Alkaline 50L & n.a. & 12.3 & 9.5 \\
\hline \multirow[t]{4}{*}{ Miscanthus 74} & Organosolv & n.d. & n.d. & n.d. \\
\hline & Acid SHS & 1.2 & 2.1 & 3.6 \\
\hline & Alkaline SHS & 12.6 & 10.3 & 9.5 \\
\hline & Alkaline 50L & n.a. & 12.2 & 9.5 \\
\hline
\end{tabular}




\subsubsection{Pulping yield}

Table 4 shows the results of the yield of the total dry matter of the solid fraction after treatment and a picture of the obtained material. The organosolv and acid-SHS treatments resulted in a more fibrous material, whereas after the alkaline treatments the samples were more similar to a cellulose pulp. The organosolv material was not used for further analysis due to the high fibrous appearance of the sample.

Two different observations were made:

- The yields of the total dry matter of the poorly digestible genotype 17 was higher than of genotype 74 for all treatments.

- Yield of dry matter was highest for the superheated steam treatments, and the acid pretreatment had a slightly higher yield compared to alkaline pretreatment. High yield of total dry matter involves the presence of non-cellulosic components that still need to be removed to obtain a cellulose pulp. But suitability of the process was not only based on yield, but also on selectivity of the process and properties of the obtained cellulose fraction.

Table 4 Yield of dry matter of the solid phases (cellulose pulp) and visual appearance.

\begin{tabular}{|c|c|c|}
\hline & Miscanth & 4 (excellent digestible) \\
\hline Start & - & \\
\hline Organosolv & 45.6 & \\
\hline Acid SHS & 73.0 & \\
\hline Alkaline 50L & 53.5 & \\
\hline
\end{tabular}




\subsubsection{Chemical composition after treatment}

The chemical composition of the solid fractions after the various pulping processes is shown in Figure 12 for Miscanthus 017 and Figure 13 for Miscanthus 074. The liquid fractions were not analysed for their composition.

The glucose content (cellulose) after treatment was increased from $38 \%$ to $60 \%$ for Miscanthus 017 and from $30 \%$ to $59 \%$ for Miscanthus 074 . After acid and SHS treatment still a high percentage of lignin (AIL) was present in the product. After alkaline treatment a high amount of xylose (hemicellulose) was still present.

For the production of a cellulose pulp, the alkaline 50L treatment of both Miscanthus genotypes was most promising as this treatment resulted in samples with the highest cellulose content, around 60 wt\%. However, more purification steps are required to obtain a pure cellulose product. Based on the composition of the starting material Miscanthus 017 is more interesting due to a higher initial cellulose content.

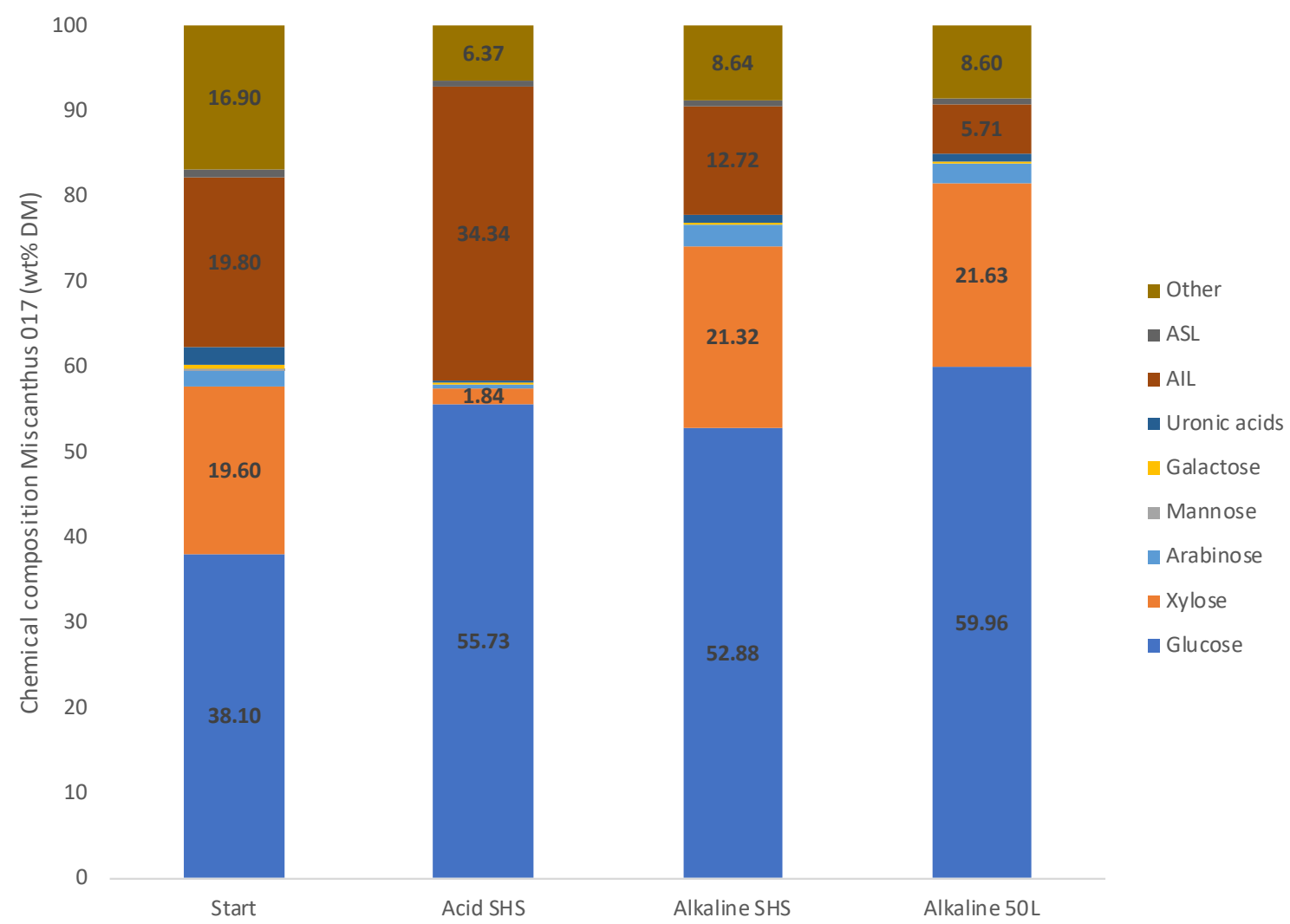

Figure 12 Chemical composition of Miscanthus 017 start material and the cellulose pulps after treatment 


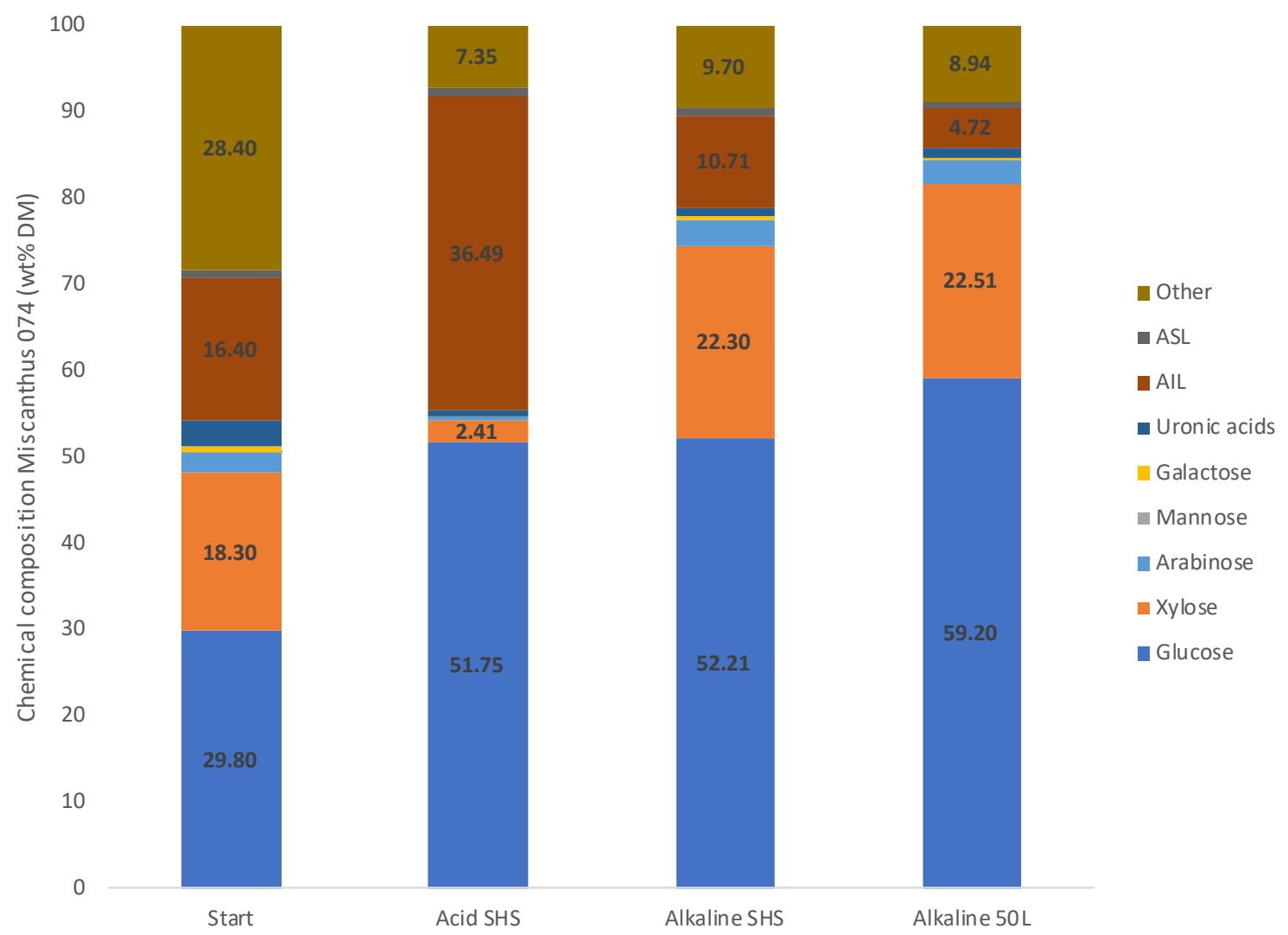

Figure 13 Chemical composition of Miscanthus 074 start material and the cellulose pulps after treatment

\subsubsection{Mass balances}

By combining dry matter yields and chemical composition of the solid fractions, mass balances can be created, providing more information on the degree of delignification and dissolution/retention of cellulose and hemicellulose. For Miscanthus 017 this is illustrated in Figure 14, for Miscanthus 074 in Figure 15. The numbers highlighted in green are the corresponding yields of glucose, xylose and lignin (AIL). A compilation of the data is shown in Table 5 and Table 6.

The two tables show that for Miscanthus the retention of cellulose (glucose) was high for all treatments. For removal of the hemicellulose (xylose) the acid SHS treatment was by far the most efficient one, as the removal of xylose was almost complete. For the other two methods around 80 wt\% of the xylose remained in the solid fraction, which is not desirable for a cellulose pulp. For removal of lignin, the alkaline processes were preferred, as during acid SHS no lignin was removed. The same trend was observed for both Miscanthus samples.

To complete these mass balances, also the liquid fractions need to be analysed to see whether sugars from cellulose or hemicellulose are dissolved and/or further degraded to furfural or organic acids. 


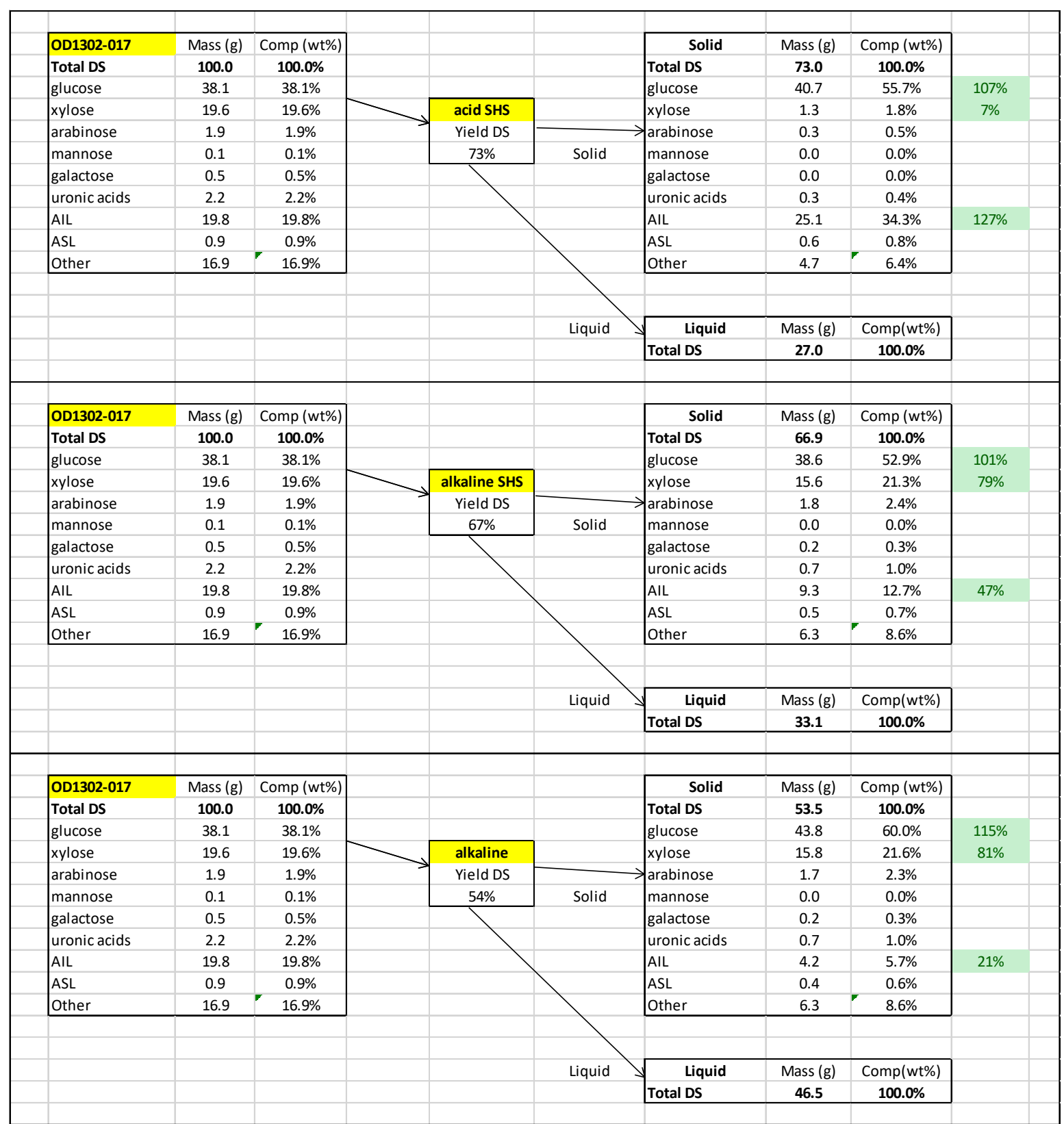

Figure 14 Mass balances for processing of Miscanthus 017 to cellulose pulp. Highlighted in green are the yields for glucan, xylan and lignin

Table 5 Compilation mass balances Miscanthus 017. Composition in g/100g DM, yield of the corresponding components in brackets in wt\% DM.

\begin{tabular}{|c|c|c|c|c|}
\hline \multirow[t]{2}{*}{ Component } & \multicolumn{4}{|c|}{ Composition (g/100 g DM) } \\
\hline & Miscanthus 017 & Acid SHS & Alkaline SHS & Alkaline 50L \\
\hline Glucose & 38 & $41(107 \%)$ & $39(101 \%)$ & $44(115 \%)$ \\
\hline Xylose & 20 & $1(7 \%)$ & $16(79 \%)$ & $16(81 \%)$ \\
\hline Lignin (AIL) & 20 & $25(127 \%)$ & $9(47 \%)$ & $4(21 \%)$ \\
\hline
\end{tabular}




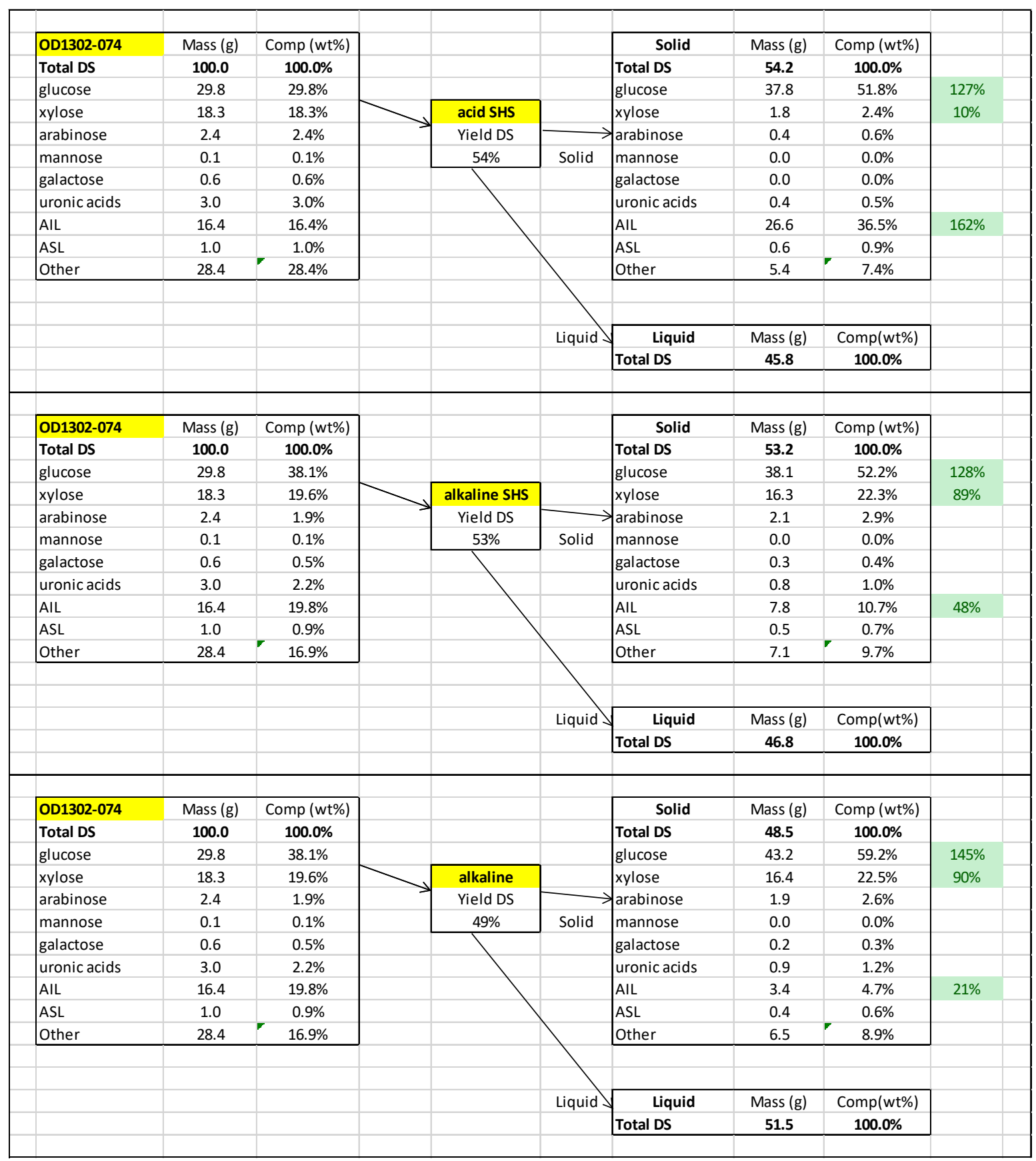

Figure 15 Mass balances for processing of Miscanthus 074 to cellulose pulp. Highlighted in green are the yields for glucan, xylan and lignin

Table 6 Compilation of mass balances Miscanthus 074. Composition in g/100 $\mathrm{g}$ DM, yield of the corresponding components in brackets in wt\% DM.

\begin{tabular}{lcccc} 
& & \multicolumn{2}{c}{ Composition $(\mathbf{g} / 100 \mathrm{~g}$ DM $)$} & \\
\hline Glucose & 30 & Acid SHS & Alkaline SHS & Alkaline $50 \mathrm{~L}$ \\
\hline Xylose & 18 & $38(127 \%)$ & $38(128 \%)$ & $43(145 \%)$ \\
\hline Lignin (AIL) & 16 & $2(10 \%)$ & $16(89 \%)$ & $16(90 \%)$ \\
\hline
\end{tabular}




\subsubsection{Fibre properties of cellulose pulps}

In this part of the study we compared different options for the production of a cellulose pulp from Miscanthus. This cellulose pulp can be further purified to dissolving cellulose but can also be used as unbleached pulp for the paper industry. The fibre properties of the celluose pulp products were determined.

To evaluate the differences, the cellulose pulps were disintegrated (to remove entanglements between fibres/fibre bundles) and consequently mechanically beaten to free the fibres from the remaining fibrebundles and to fibrillate the fibres. The mechanical properties of the hand sheets made from these pulps at specific beating degrees ( 30 and $50 \mathrm{SR}$ ) provides insight in the morphology of the pulps after the chemical treatments and on the performance of these pulps for the application in paper products.

The beating degree of a cellulose pulp is an index to reflect water filtration degree. In general, the higher the beating degree, the lower the filtration speed. The beating degree of an unbeaten commercial chemical pulp is well below $20^{\circ} \mathrm{SR}$, as beating (which is required to get fibres suitable for paper making) will result in an increase in beating degree.

The beating degree measured after both alkaline treatments (treatments 3 and 4) corresponded with this number (see Figure 16). The beating degree of the acid treated pulp (treatment 2) was higher, most likely due to the formation of an excess of small particles, besides the fibres and fibre bundles. Upon beating, the beating degree of the pulps increased. Treatment 3 resulted in a pulp that requires less beating than treatment 4 to reach desired beating degree (30-40 ${ }^{\circ} \mathrm{SR}$ ). Beating degree increase in the acid treated pulp was slow, maybe because fibrillation and separating of the fibre bundles into individual fibres was more difficult while the lignin structure in the pulp was still present.

Comparing the increase in beating degree between the two Miscanthus species, beating development increase was faster for sample 17 ("poor"), the sample with the highest initial lignin and cellulose content.
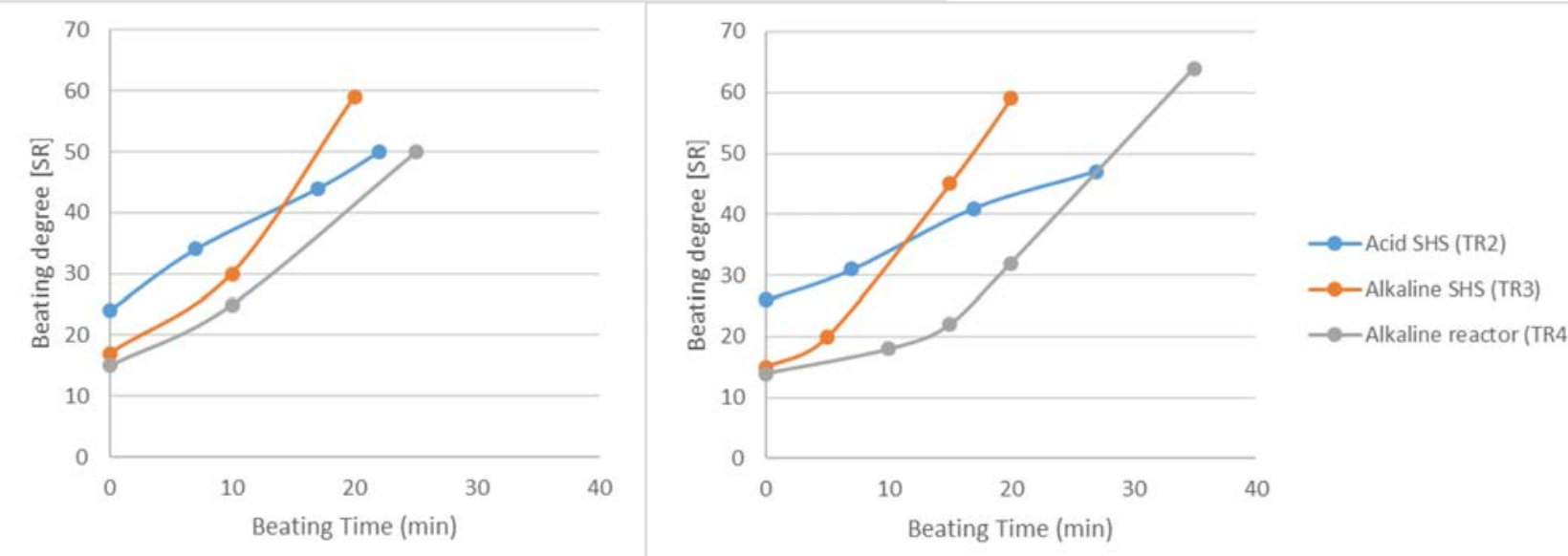

\section{Figure 16 Beating degree as function of beating time of Miscanthus 017 (left) and 074 (right)}

During the mechanical treatment in the valley beater, foaming occurred for the pulps produced using the SHS reactor (treatments 2 and 3). No foaming was observed for the pulps produced in the 50L reactor (treatment 4). Most likely, this difference in foaming behaviour was due to a different washing sequence after treatment 2 and 3 compared to treatment 4 . As this suggests that washing was more vigorous after treatment 4, most likely the smaller yield of treatment 4 compared to treatment 2 and 3 was (partly) due to the more vigorous washing stage. Vigorous washing results in loss of fines and dissolved materials. 


\subsubsection{Mechanical properties of hand sheets}

The bulk (reciprocal density) of the handsheets shows whether the pulp consists of single fibres or larger particles or fibre bundles. Bulk diminishes upon increased beating. Bulk of the handsheets made as function of beating degree is shown in Figure 17. For chemical pulps of hard- and softwood a bulk between 1 and $1.5 \mathrm{~cm}^{3} / \mathrm{g}$ is normally achieved.

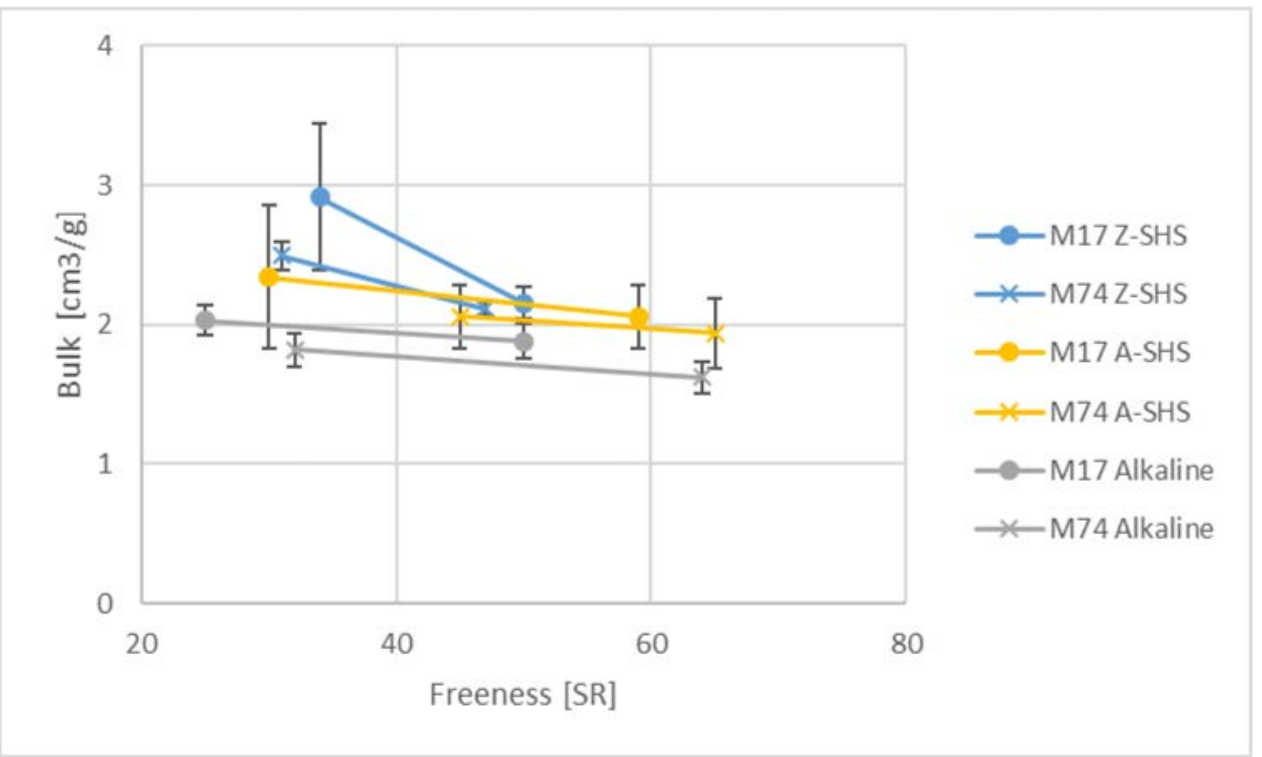

\section{Figure 17 Bulk as function of beating degree after different pulping treatments for Miscanthus 017 ("poor") and Miscanthus 074 ("excellent")}

The results show that bulk is lower for Miscanthus 074 than for Miscanthus 017, indicating that upon pulping 074 is broken down into fibres more easily than 017 . The acid treatment was less effective in breaking down the fibre bundles into fibres compared to the alkaline treatments.

The Miscanthus pulps were not yet fully disintegrated into fibres, resulting in higher bulk values. The measured bulk levels of 1.5-2.5 is more consistent with semi-mechanical wood pulps. Apparently, the used pulping treatments were less severe than the chemical pulping treatments of commercial pulps.

\subsubsection{Physical properties of hand sheets}

The measurements of surface roughness and porosity of the produced hand sheets (see appendix 1) showed that pulping of the Miscanthus samples resulted in larger particles and fibre bundles compared to commercial chemical pulps. Both values were outside the range of chemical pulps. The SCT strength and tear strength also showed that the cellulose pulp properties were in between mechanical and chemical pulps. This demonstrated that the chemical pulping performed on Miscanthus in these trails was not severe enough to obtain results comparable to commercially available chemical pulps.

The tensile strength properties (represented as breaking length) of the Miscanthus pulps are presented in Figure 18. At lower beating degrees the standard deviation in the tensile strength was rather large, due to the larger particles present in the handsheets. There was no clear difference between the two Miscanthus types.

The alkaline treated pulps had far higher tensile strengths compared to the acid treated pulps. Tensile strength of the acid treated pulps was below recycled paper (mixed waste) quality. The acid treatment did not result in a pulp acceptable for paper production, accept as filler or for decoration purposes. Tensile strength of the alkaline treated pulps was high compared to recycled paper, however well below the tensile strength of hard- and softwood chemical pulps. Previous results with alkaline pulping of grass also resulted in better tensile strength. Again, this shows that the conditions of the chemical pulping in this study (alkaline, treatment 4) were not severe enough. 


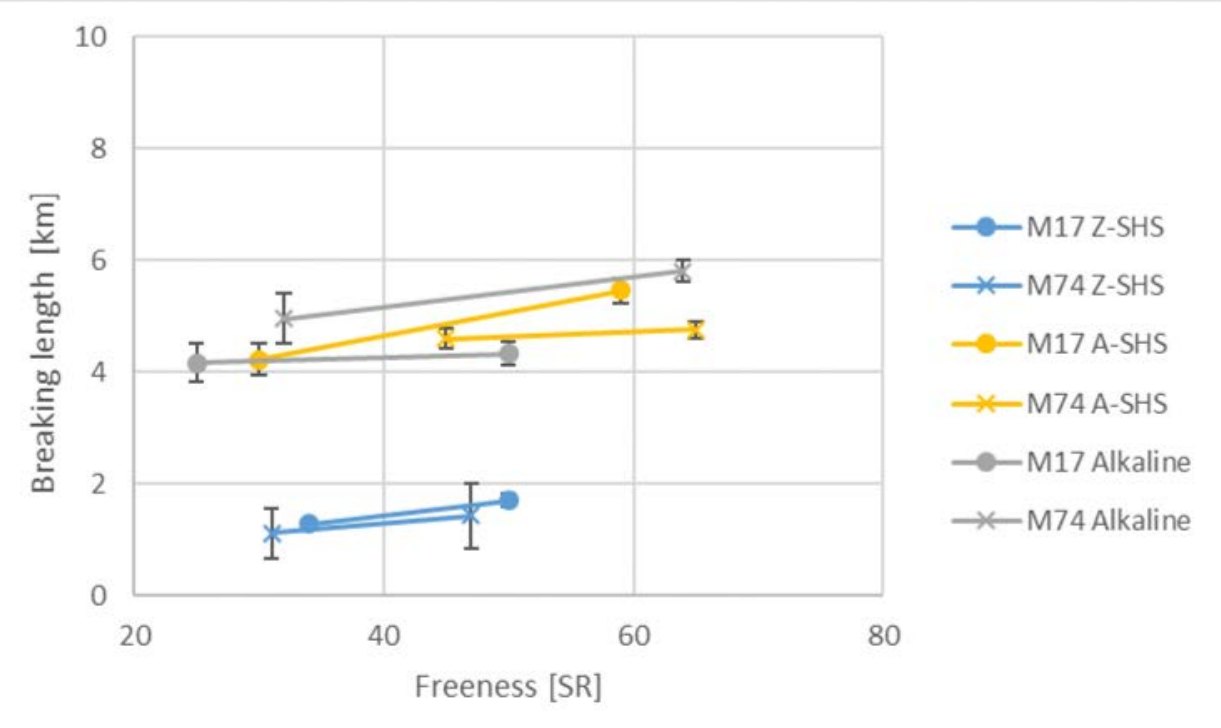

Figure 18 Breaking length of the produced hand sheets as function of beating degree

\subsubsection{Value for pulp production}

The properties of the cellulose pulps from Miscanthus were compared to existing wood pulps (obtained from commercial processes) and pulps made from grass from nature (own data).

In Figure 19 the tensile index (representing the tensile strength) of the different Miscanthus pulps is compared to commercial chemical pulps from softwood and hardwood. The tensile strength of the produced Miscanthus pulps was low compared to commercial pulps, also compared to chemical pulps made from grass.

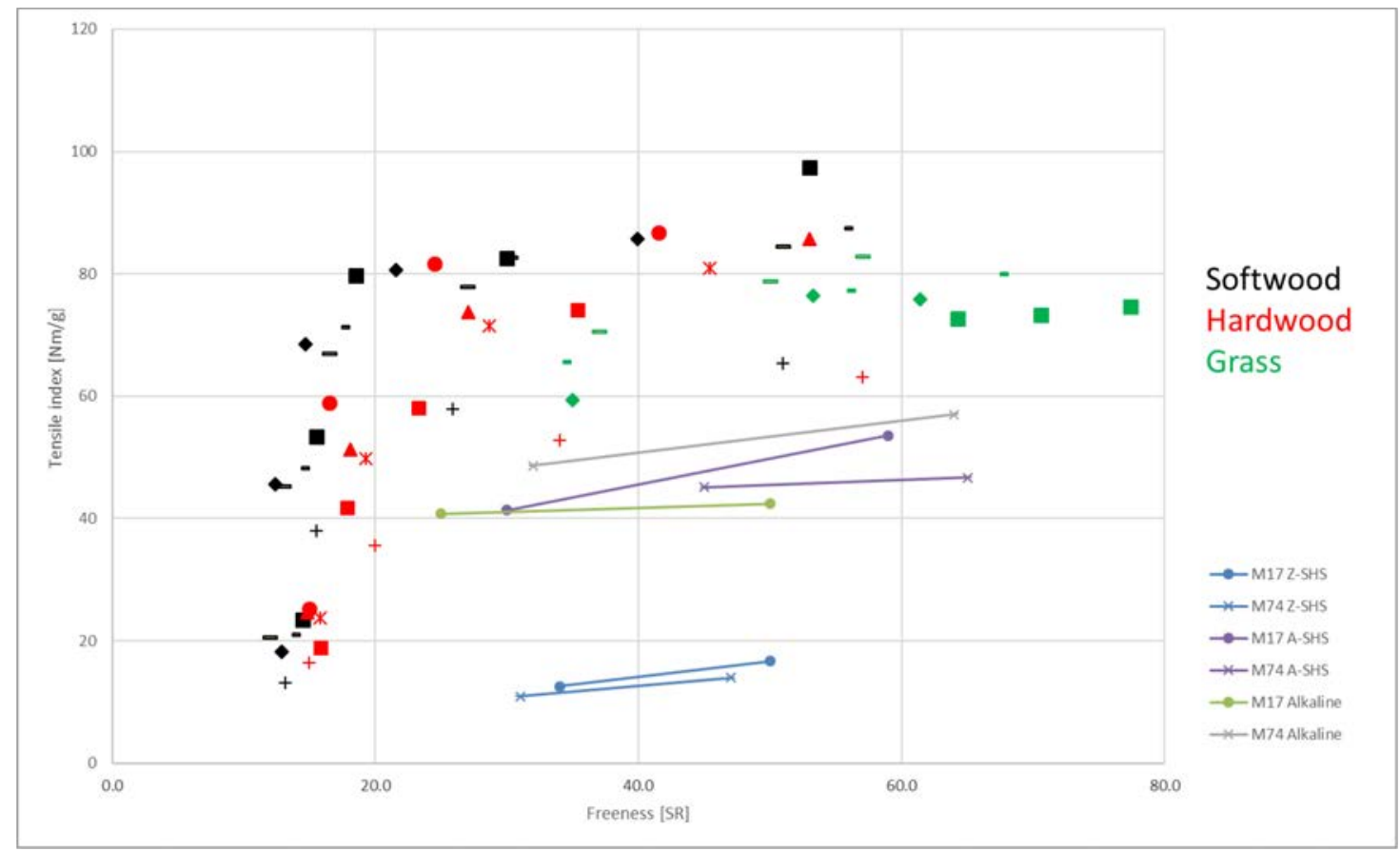

Figure 19 Tensile index of cellulose pulps from Miscanthus compared to commercial chemical pulps from softwood and hardwood and compared to pulp from grass 
In Figure 20 the tensile index of the different Miscanthus pulps is compared to commercial mechanical and recycled pulps. The tensile index of the produced alkaline Miscanthus pulps was higher than the strength of recycled paper, (chemi-)mechanical wood based pulps and mechanically produced pulps from grass.

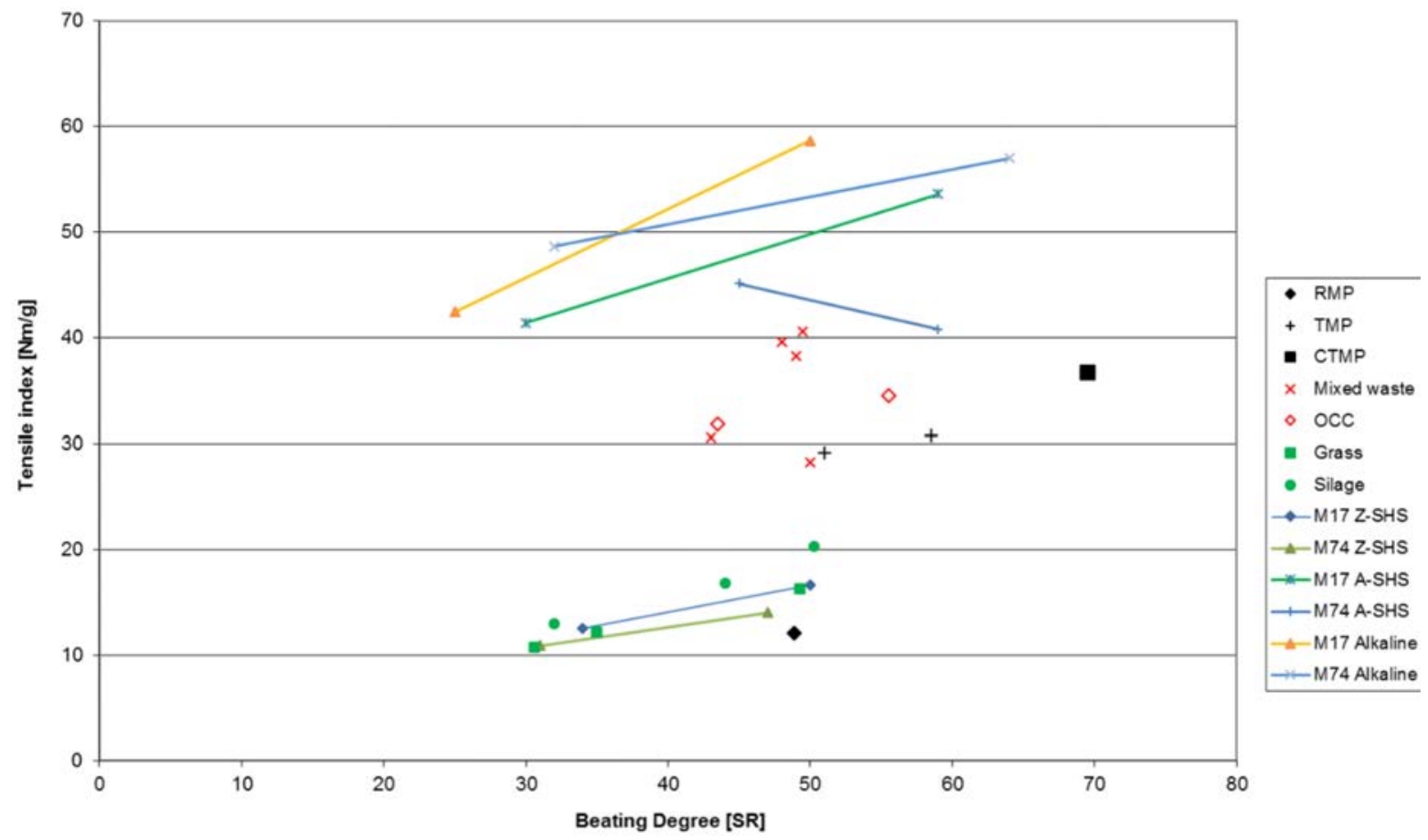

Figure 20 Tensile index of cellulose pulps from Miscanthus compared to commercial mechanical pulps and recycled pulps. RMP=refined mechanical pulp, TMP=thermo mechanical pulp, CTMP=chemo thermo mechanical pulp, OCC=old corrugated containers 


\subsection{Fermentable sugars from Miscanthus}

\subsubsection{Introduction}

In this paragraph the production of fermentable sugars from Miscanthus is described. In paragraph 3.3.2 the production of sugars from all 8 genotypes is described, where an acid treatment was done on coarse particles, followed by an enzymatic hydrolysis. In paragraph 3.3.3 the same experiments were repeated with sample 074 ("excellent") with a reduced particle size. In paragraph 3.3.4 both 017 and 074 were used to study the acid SHS, alkaline SHS and alkaline treatment, followed by enzymatic hydrolysis to produce the sugars.

\subsubsection{Acid treatment with coarse particles}

All 8 Miscanthus genotypes were tested as feedstock to produce fermentable sugars. An acid pretreatment at $160^{\circ} \mathrm{C}$ was done to reduce the recalcitrance of the lignocellulose to enzymatic degradation. Subsequently an enzymatic hydrolysis was performed to produce fermentable sugars. All experiments were done with coarse fibres as shown in Figure 4.

After treatment and centrifugation, the amount of monomeric sugars (glucose and xylose) in the liquid phases was determined. The yields of glucose and xylose after acid hydrolysis and enzymatic hydrolysis is illustrated in Figure 21.
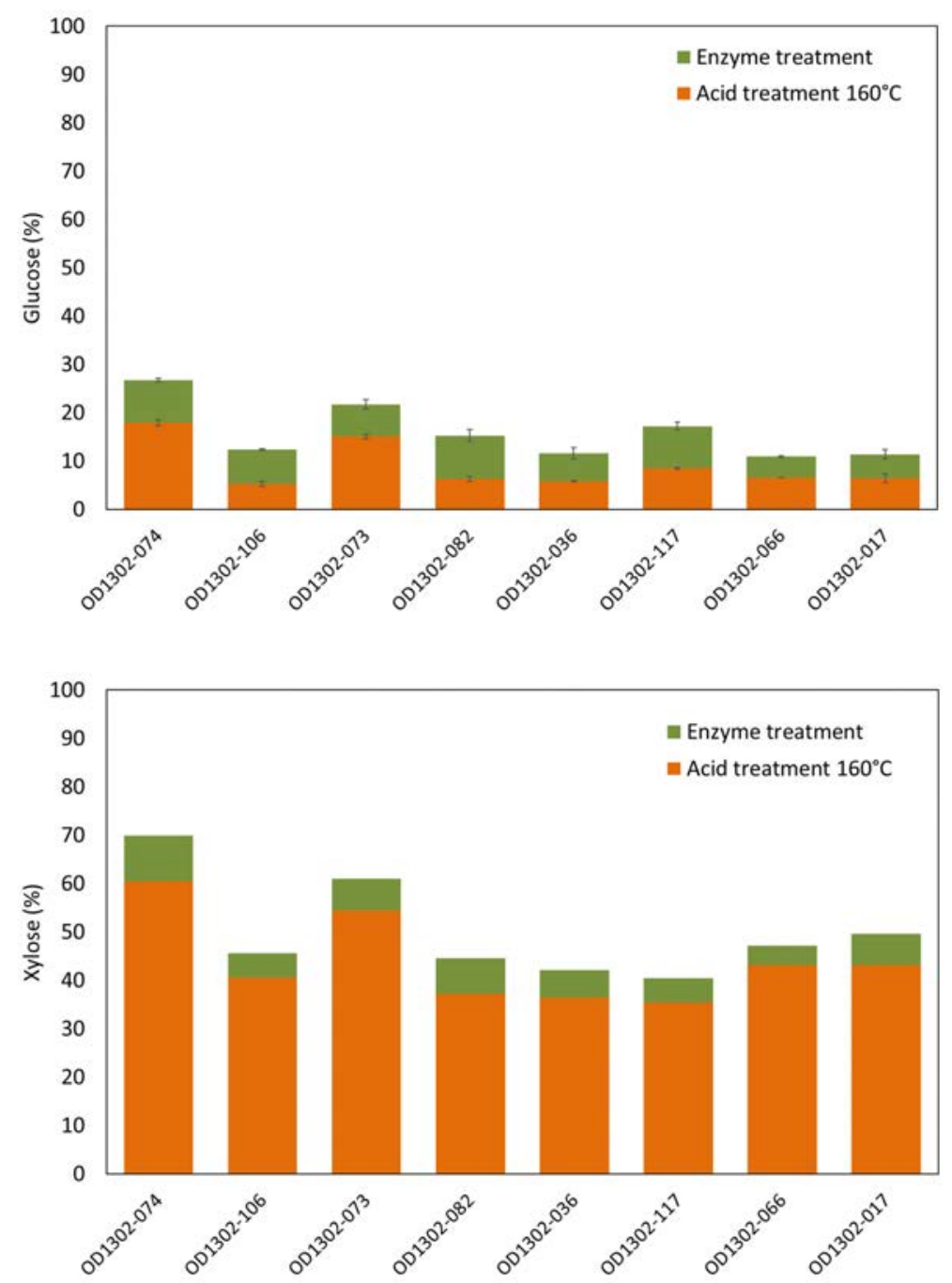

Figure 21 Glucose (top) and xylose (bottom) yields in wt\% of glucose or xylose input after acid and enzyme treatment (all 8 Miscanthus samples) 
The overall glucose yield was very low $(<30 \mathrm{wt} \%)$; the highest yield was obtained for Miscanthus 074 (excellent digestible) and the lowest for Miscanthus 017 (poor digestible). The xylose yield was much higher than the glucose yield (40-70\%). Solubilisation of hemicellulose into xylose is particularly caused by the acid treatment, as the hemicellulose fraction is more prone to acid hydrolysis than the recalcitrant cellulose. The highest xylose yield was also obtained for Miscanthus 074.

In Figure 22 the relationship between digestibility, as defined in Table 1, and glucose/xylose yield is presented. Although there seems to be a positive correlation, this was mainly caused by the results of genotype 074.

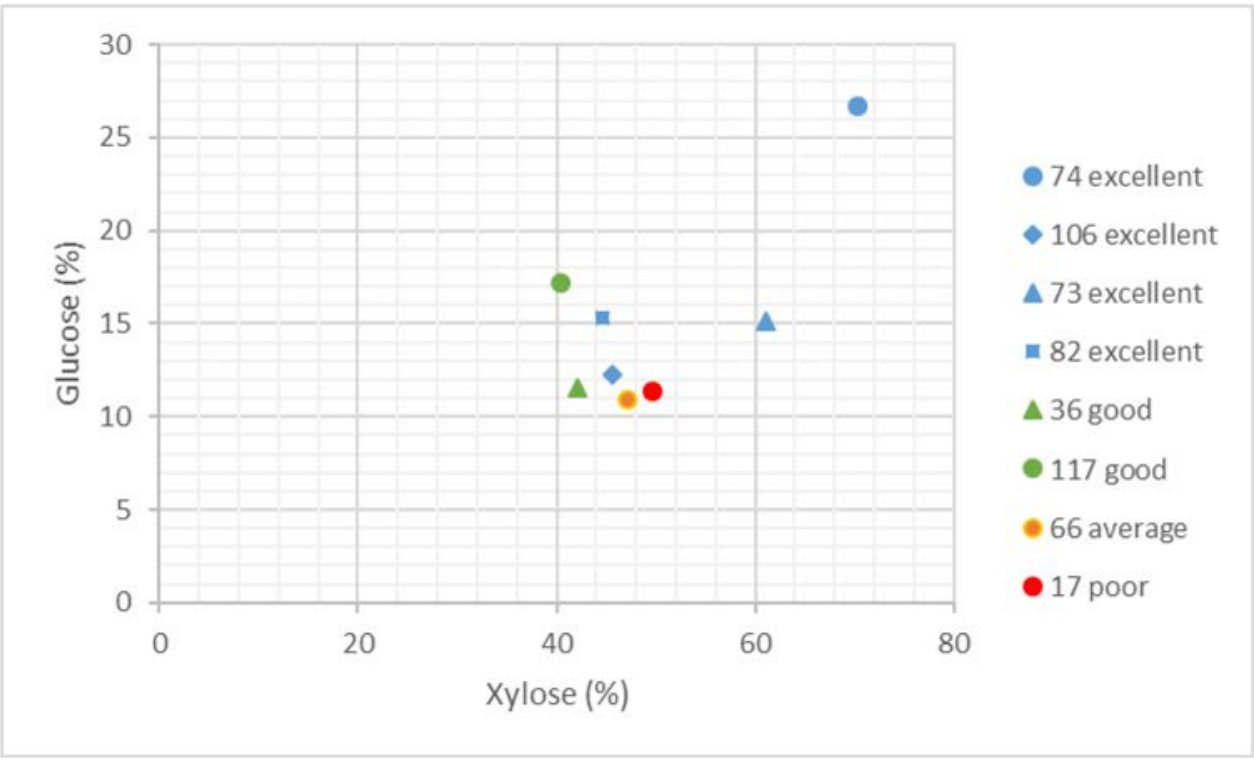

Figure 22 Digestibility versus glucose and xylose yields

\subsubsection{Reduction of particle size and increasing intensity acid hydrolysis}

Compared to other types of lignocellulosic biomass, the glucose and xylose yields from Miscanthus were relatively low. After the enzymatic hydrolysis the solid residue was mainly fibrous material (Figure 23, left picture), most likely rich in cellulose and lignin. This suggested that a large particle size might contributed to the recalcitrance against enzymatic hydrolysis and that particle size reduction enhances glucose and xylose yields.
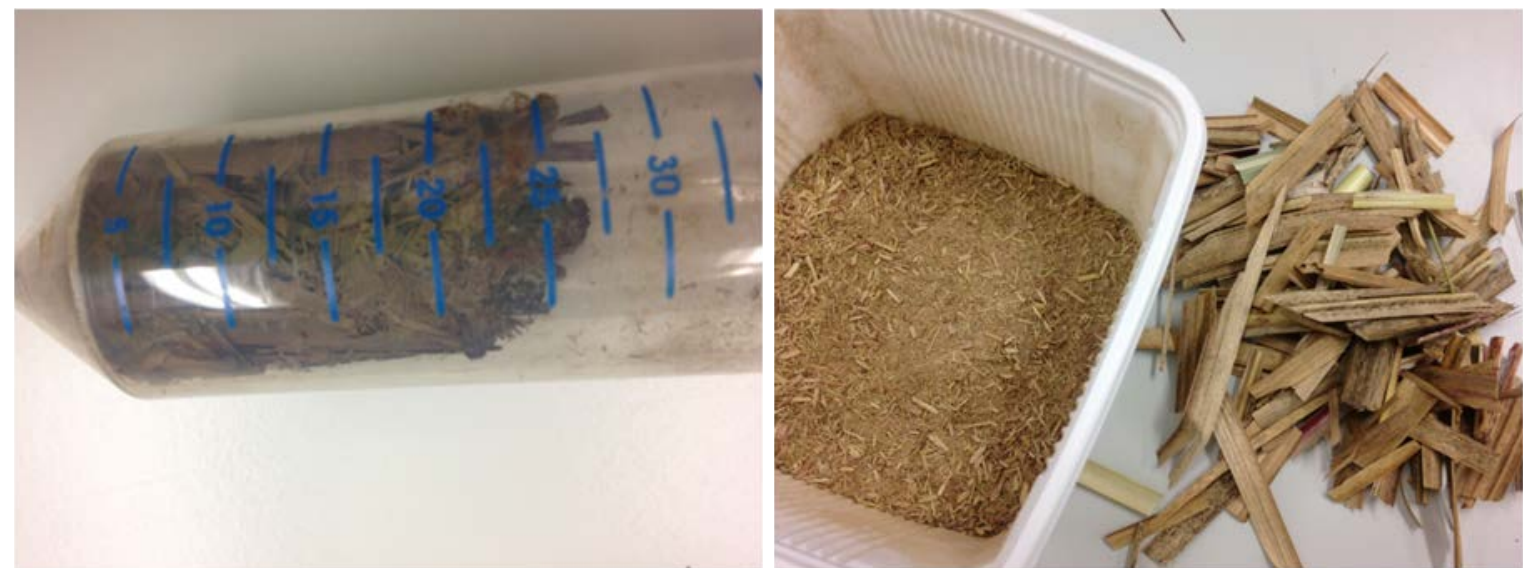

Figure 23 Miscanthus after acid pre-treatment at $160^{\circ} \mathrm{C}$ and enzymatic hydrolysis (left picture) and milled sample of Miscanthus 074 
Additional experiments were performed to improve the solubility of the sugars. Miscanthus genotype 074 was milled (Figure 23, right picture), soaked 24 hours in acid before pre-treatment and a higher temperature of $180^{\circ} \mathrm{C}$ instead of $160^{\circ} \mathrm{C}$ was used. After treatment and centrifugation, the solubilised sugars were measured in the liquid fractions. The results are shown in Figure 24.
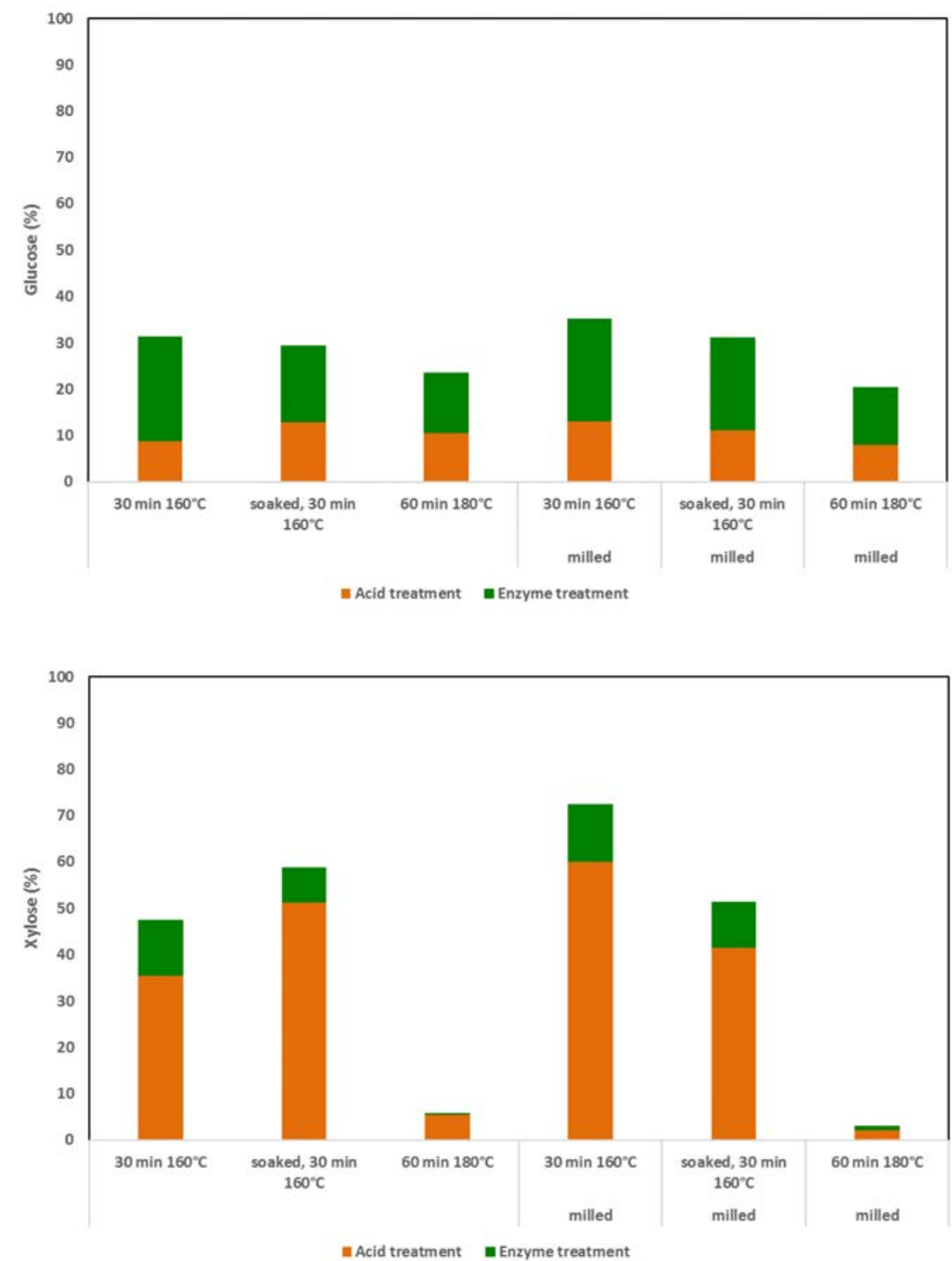

Figure 24 Glucose (top) and xylose (bottom) yields in wt\% of glucose or xylose input after acid and enzyme treatment of Miscanthus 074

Pre-soaking and increase in temperature did not result in a higher glucose or xylose yield for the milled sample. Size reduction of the sample by milling did not result in a higher glucose yield but a slightly higher xylose yield. A treatment at very high temperature $\left(180^{\circ} \mathrm{C}\right.$ instead of $\left.160^{\circ} \mathrm{C}\right)$ resulted in a totally breakdown of the material. Almost no xylose was detected in the liquid phases because xylose was probably further degraded to furfural and organic acids.

\subsubsection{Enzymatic hydrolysis of cellulose pulps}

The obtained cellulose pulps of treatment 2 (acid SHS), 3 (alkaline SHS) and 4 (alkaline 50L) (as described in the previous paragraph) were also subjected to enzymatic hydrolysis for 24 and 72 hours with the enzyme CTec2 from Sigma. Figure 25 and Figure 26 are pictures of the material before and after enzymatic hydrolysis. 


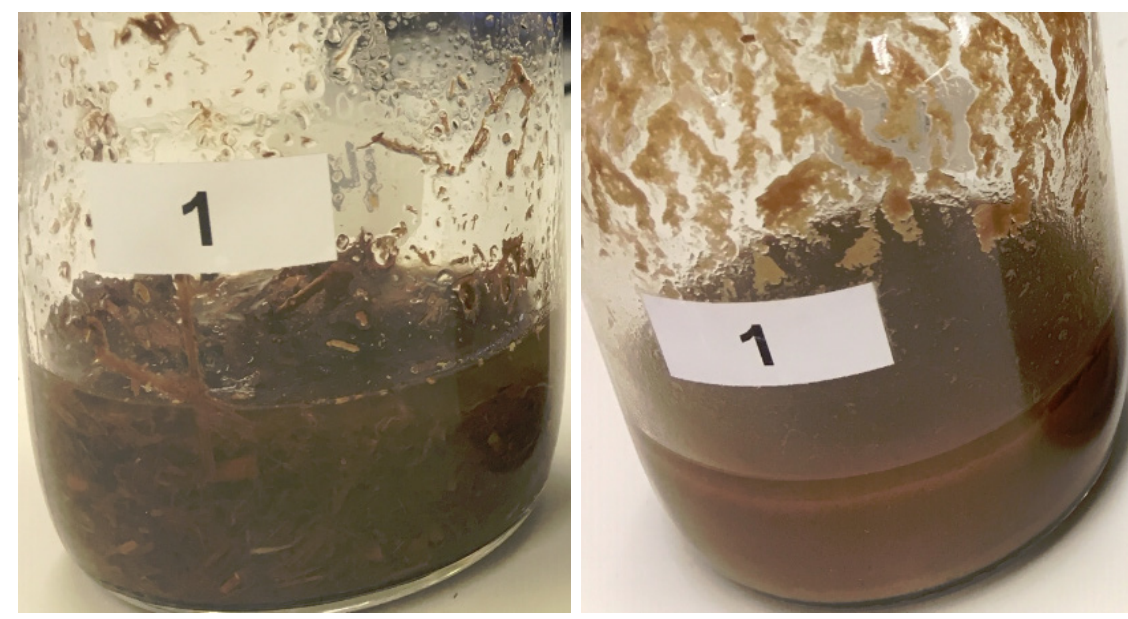

Figure 25 Acid-SHS sample of Miscanthus 074 before (left picture) and after (right picture) enzymatic hydrolysis

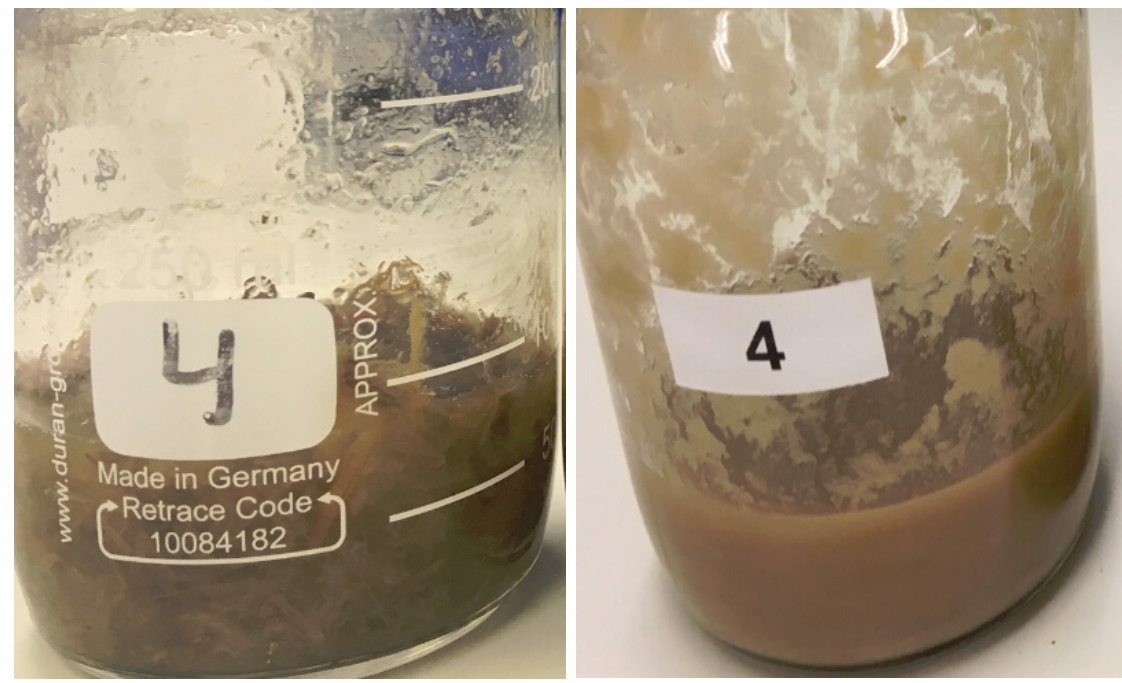

\section{Figure 26 Alkaline-SHS of Miscanthus 074 before (left picture) and after (right picture) enzymatic hydrolysis}

After centrifugation the concentration of monomeric sugars (glucose and xylose) was determined in the liquid. The percentage of solubilised sugars was calculated from the amount of sugars present in the cellulose pulps after treatment (for composition see Figure 12 and Figure 13), so not of the starting material.

Based on the results of paragraph 3.2.4 (chemical composition after treatment), the cellulose pulps of Miscanthus 017 were high in cellulose content but very low in hemicellulose content for the acid-SHS pulp. The alkaline pulps had a reduced lignin content, possibly beneficial for glucose release after enzymatic hydrolysis.

Glucose and xylose yield after enzymatic hydrolysis of Miscanthus 17 after $24 \mathrm{~h}$ and $72 \mathrm{~h}$ is presented in Figure 27. These graphs show a limited glucose release after enzymatic hydrolysis (10-15 wt\%), indicating that these cellulose pulps were less suitable for the production of glucose. For xylose only the alkaline treated pulps released a substantial amount of xylose: 40 wt\% from the alkaline-SHS pulp and $30 \mathrm{wt} \%$ of the alkaline pulp. For acid SHS most of the xylose was already removed from the pulp. 


\section{Miscanthus 17, glucose}
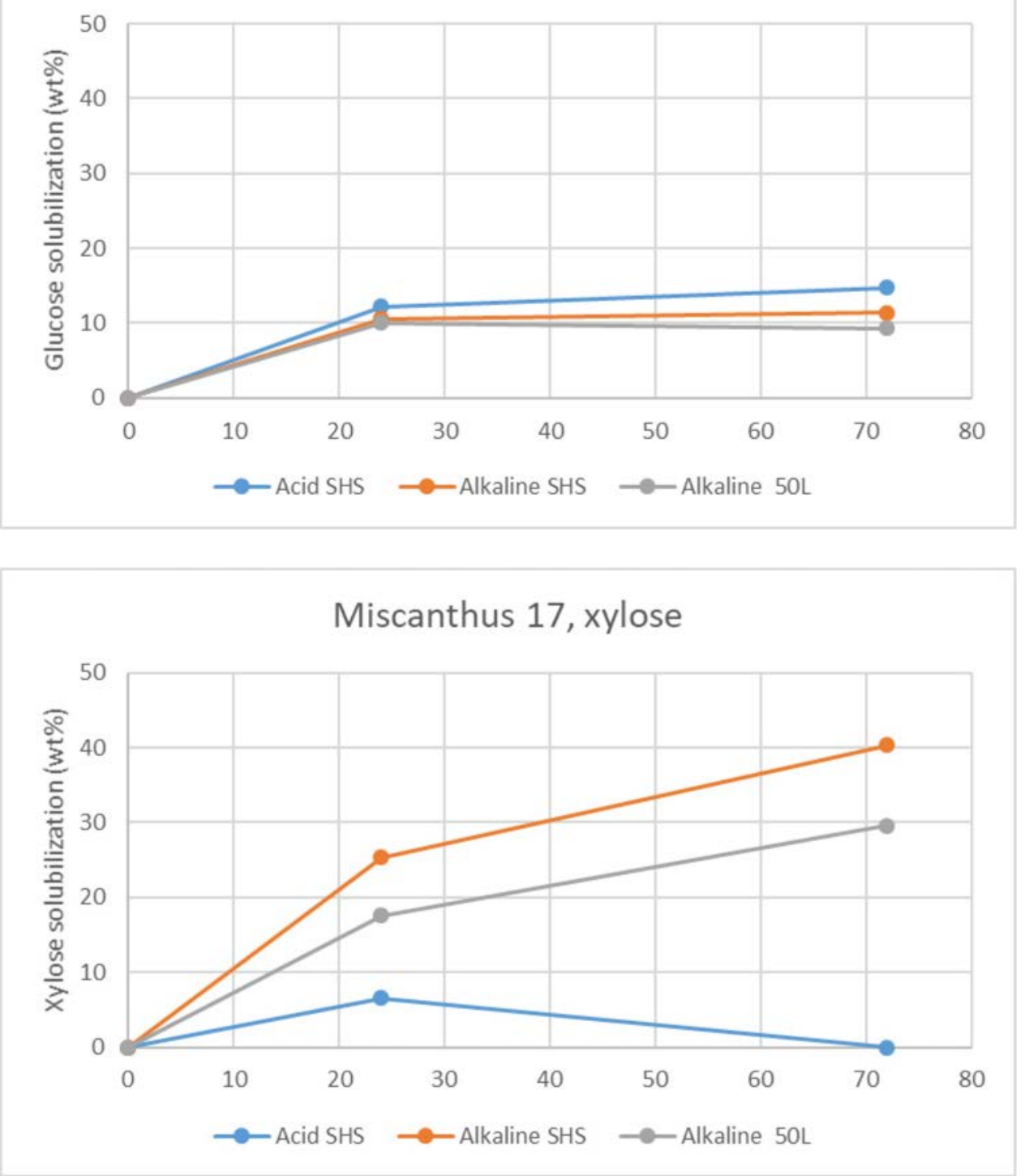

Figure 27 Glucose and xylose solubilization after enzymatic treatment, based on the amount of glucose present in the cellulose pulps of Miscanthus 017 after pretreatment

For Miscanthus 074 the results are shown in Figure 28. Based on the results of paragraph 3.2.4 (chemical composition after treatment), the cellulose pulps of Miscanthus 074 were high in cellulose content but very low in hemicellulose content for the acid-SHS pulp. The alkaline pulps had a reduced lignin content, possibly beneficial for glucose release after enzymatic hydrolysis. The graphs show a glucose release due to enzymatic hydrolysis of 18-28 wt\%, higher than for the Miscanthus 017 samples. For xylose only the alkaline treated pulps contained a substantial amount of xylose. Enzymatic hydrolysis released 30 wt\% of the available sugars from the alkaline-SHS pulp and 40 wt $\%$ of the alkaline $50 \mathrm{~L}$ pulp. 

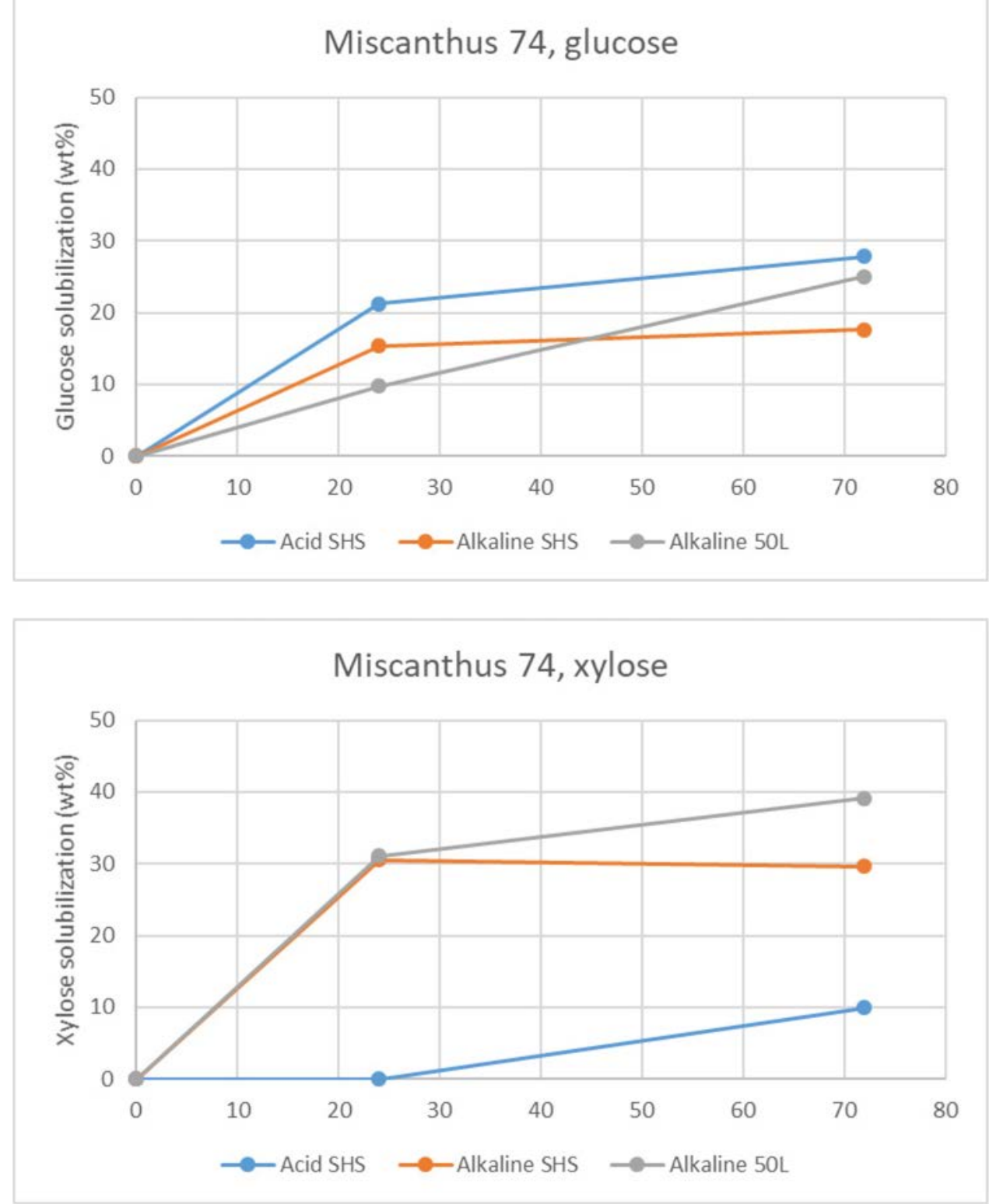

Figure 28 Glucose and xylose solubilisation after enzymatic treatment, based on the amount of glucose present in the cellulose pulps of Miscanthus 074 after treatment.

\subsubsection{Comparison between acid hydrolysis, superheated steam treatments and alkaline pulping.}

The amount of fermentable sugars produced after acid hydrolysis at $160{ }^{\circ} \mathrm{C}$ followed by enzymatic hydrolysis, as described in paragraph 3.3.2 and 3.3.3, is much higher than the amount of fermentable sugars after enzymatic hydrolysis after SHS and alkaline pulping. This is due to the removal of the sugar-containing liquid fraction after pulping. Especially for the acid-SHS treatment, this liquid fraction will contain a substantial amount of $\mathrm{C} 5$-sugars or $\mathrm{C} 5$-sugar degradation products.

In Figure 29 the sugar yield after enzymatic hydrolysis is given of all 4 pulping methods studied. A total sugar balance cannot be made as the sugar concentrations in the first liquid fractions produced were not measured.

Based on the mass balances in Figure 14 and Figure 15 one can assume that cellulose remained intact after pulping and that hydrolysis of cellulose to glucose was only achieved by enzymatic hydrolysis. Under these conditions, the acid-SHS treatment resulted in the highest glucose yield, and glucose yields were higher for the Miscanthus 074 samples than for the Miscanthus 017 samples. 

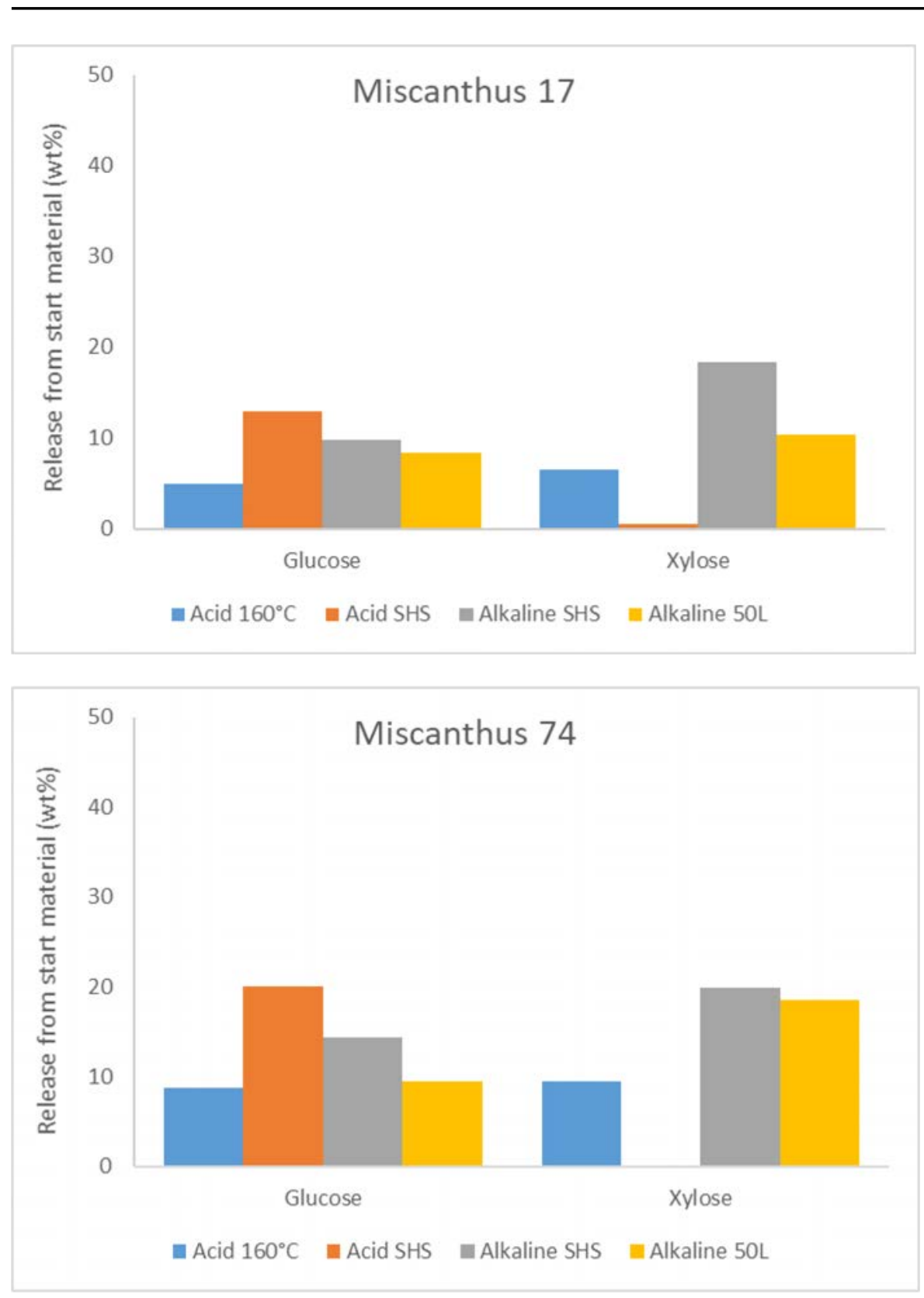

Figure 29 Glucose and xylose yield after enzymatic hydrolysis, based on starting material 


\section{Conclusions and recommendations}

Eight genotypes of Miscanthus sinensis were provided by WPR with differences in composition and digestibility. The eight genotypes showed significant differences in chemical composition. A correlation between glucose and lignin content and digestibility could be present:

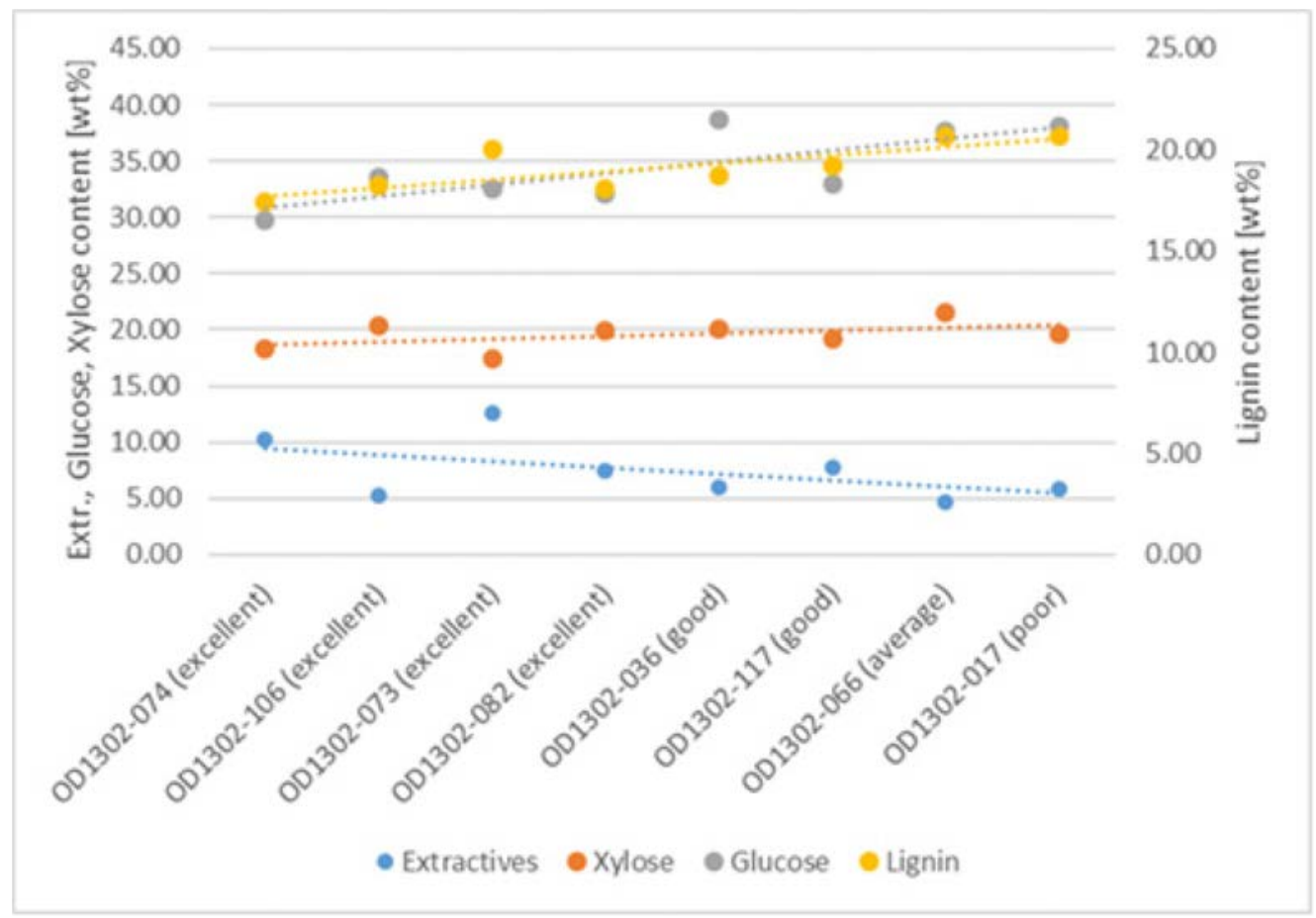

\section{Fermentable sugars}

The 8 genotypes were subjected to a two-stage process to produce fermentable sugars. The first stage consisted of an acid treatment at elevated pressure and temperature, the second stage of an enzymatic hydrolysis. Clear differences in the amount of fermentable sugars obtained were found. The genotype with the highest digestibility (074, lowest amount of cellulose and lignin) also resulted in the highest amount of fermentable sugars. Correlation between the digestibility and fermentable sugar yield of the other genotypes was less clear.

Two genotypes (017 and 74) were also subjected to three other pulping processes as first stage (acid super heated steam (SHS), alkaline SHS and alkaline pulping at $120^{\circ} \mathrm{C}$ ), followed by a second stage of enzymatic hydrolysis. Similar results were obtained: the genotype with the highest digestibility (074, lowest amount of cellulose and lignin) also resulted in the highest amount of glucose. Release of xylose was similar.

- $\quad$ The resulting cellulose pulps of Miscanthus 017 were high in cellulose content but very low in hemicellulose content for the acid-SHS pulp. The alkaline pulps had a reduced lignin content. Glucose and xylose yield after enzymatic hydrolysis showed a limited glucose release (10-15 $w t \%)$, and a moderate xylose release (30-40 wt\%) for the alkaline treated pulps. For acid SHS most of the xylose was already removed from the pulp during the SHS treatment.

- $\quad$ The results for Miscanthus 074 were comparable to 017 , with a slightly higher glucose release (1828 wt\%).

Cellulose pulp

Another part of the study was the conversion of two genotypes (Miscanthus 074 and 017) to cellulose pulp by four different methods: prehydrolysis followed by organosolv, acid super heated steam (SHS, alkaline SHS and alkaline pulping at $120^{\circ} \mathrm{C}$. 
The glucose content (cellulose) after treatment was increased from 38\% to $60 \%$ for Miscanthus 017 and from $30 \%$ to $59 \%$ for Miscanthus 074. After acid and SHS treatment still a high percentage of lignin (AIL) was present in the product. After alkaline treatment a high amount of xylose (hemicellulose) was still present.

For the production of a cellulose pulp, the alkaline 50L treatment of both Miscanthus genotypes was most promising as this treatment resulted in samples with the highest cellulose content, around 60 $w t \%$. However, more purification steps are required to obtain a pure cellulose product. Based on the composition of the starting material Miscanthus 017 is more interesting due to a higher initial cellulose content.

\section{Hand sheets}

The fibre properties of cellulose pulps and the mechanical- and physical properties of hand sheets were analysed. The cellulose-enriched samples were disintegrated, mechanically beaten and handsheets were prepared. The properties of these handsheets were determined to provide insight in the morphology of the pulps after chemical treatment, and on the performance for application in paper products.

Results showed that the acid-SHS treatment was less effective in breaking down the fibre bundles of the Miscanthus biomass into fibres compared to the alkaline treatments. The acid treated cellulose pulp was not fully disintegrated into fibres, resulting in a high bulk value. Also, the bulk levels of the alkaline treated pulps were at the higher side of chemical wood pulps, showing that the pulping treatments applied in this study were less severe than chemical pulping treatments of commercial pulps. Results showed that bulk was lower for Miscanthus 074 than for 017 , indicating that upon pulping 074 is broken down into fibres more easily than 017 .

The paper properties showed that opening of the fibre structure of Miscanthus was most effective for the alkaline benchmark process. The SHS treatments did not succeed in breaking all fibre bundles into single fibres. Results corresponded with the observation that both alkaline pulping stages were not severe enough to produce a chemical unbleached pulp. The acidic SHS process only removed the hemicellulose from the lignocellulosic structure. The resulting pulp showed very poor paper forming properties. Overall, paper properties of the two Miscanthus samples were similar. Larger differences were observed between the various pulping processes.

Mechanical strength of the papers produced after beating in a valley beater showed that the alkaline pulps did not show the quality of chemical unbleached pulps. The properties were comparable to (chemi-) mechanical pulps. The mechanical properties of the acid SHS pulp were at the lower end of mechanical pulp properties.

\section{Value of cellulose pulps from Miscanthus}

The combination of acid soaking with superheated steam resulted in an almost complete removal of the hemicellulose fraction (xylose), with a cellulose/lignin enriched fraction as solid residue. This solid residue might be a suitable material for the production a dissolving cellulose pulp, as only the lignin fraction needs to be removed. Prerequisite for this is a high degree of polymerisation (DP) of the cellulose. Some indications were found that the degree of polymerisation of the cellulose fraction was sharply decreased (which is often the case for acid processes), making the application as dissolving cellulose less prevalent. In addition, the extracted hemicellulose (xylose) from Miscanthus might be used as raw material for chemical modifications to e.g. xylitol, but for that an analysis is required of the liquid fraction. Due to the severity of the process, it is also possible that xylose is further converted to furfural or (volatile) organic acids and that milder conditions are also an option.

The use of the superheated steam process in combination with an alkaline or acidic soaking does not result in fibres with properties comparable to unbleached chemical pulps. The properties of the pulp resulting from the alkaline superheated steam process were comparable with chemi-mechanical pulps. Some reduction of the amount of alkali used may result in a relatively cheap process to produce chemi-mechanical pulps from Miscanthus. 


\section{Recommendations}

- Measure sugar concentration in the liquid fractions after pulping/pretreatment, to complete the mass balance

- $\quad$ Perform a less severe acid SHS treatment to maintain cellulose quality

- $\quad$ Perform a more severe alkaline benchmark pulping process for a better comparison with commercial cellulose pulps

- Compare Miscanthus with another type of lignocellulosic biomass under same experimental conditions 


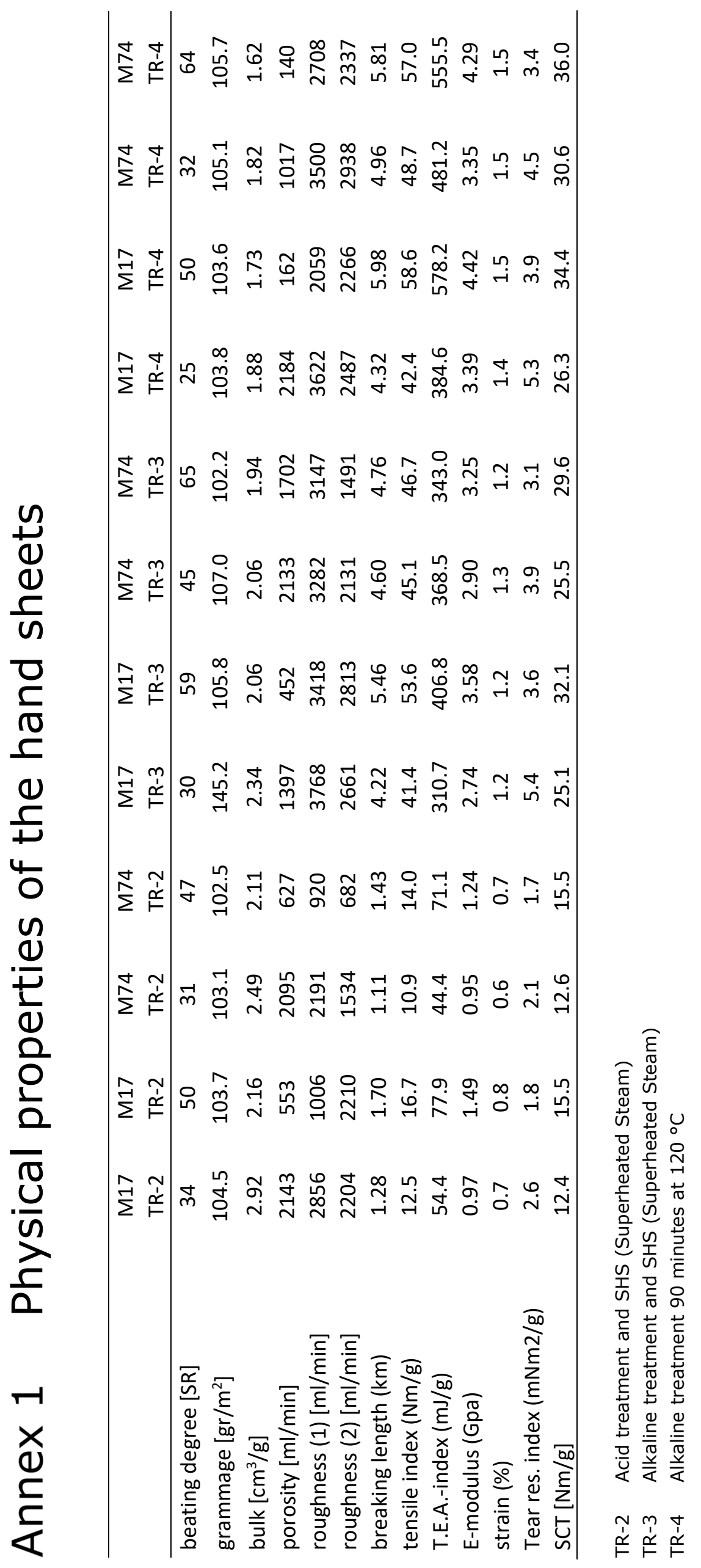





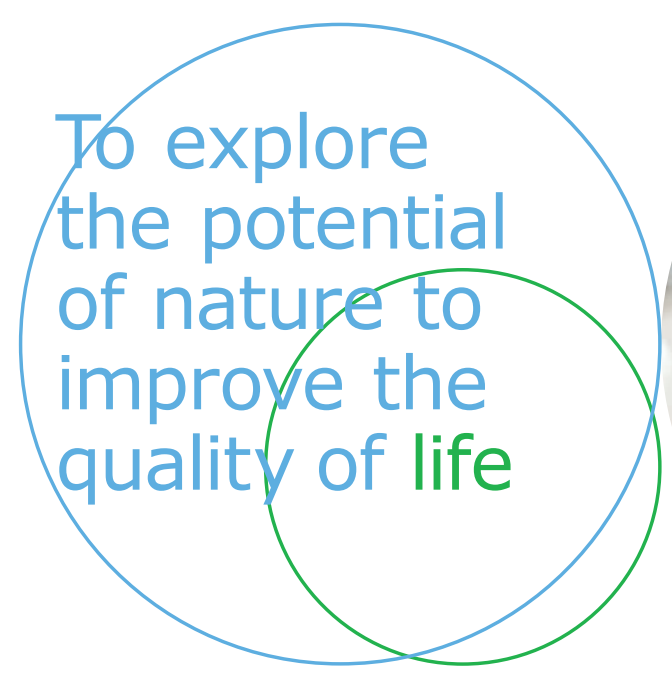

Wageningen Food \& Biobased Research Bornse Weilanden 9

6708 WG Wageningen

The Netherlands

www.wur.eu/wfbr

Einfo.wfbr@wur.nl

Report 2072

ISBN 978-94-6395-476-1

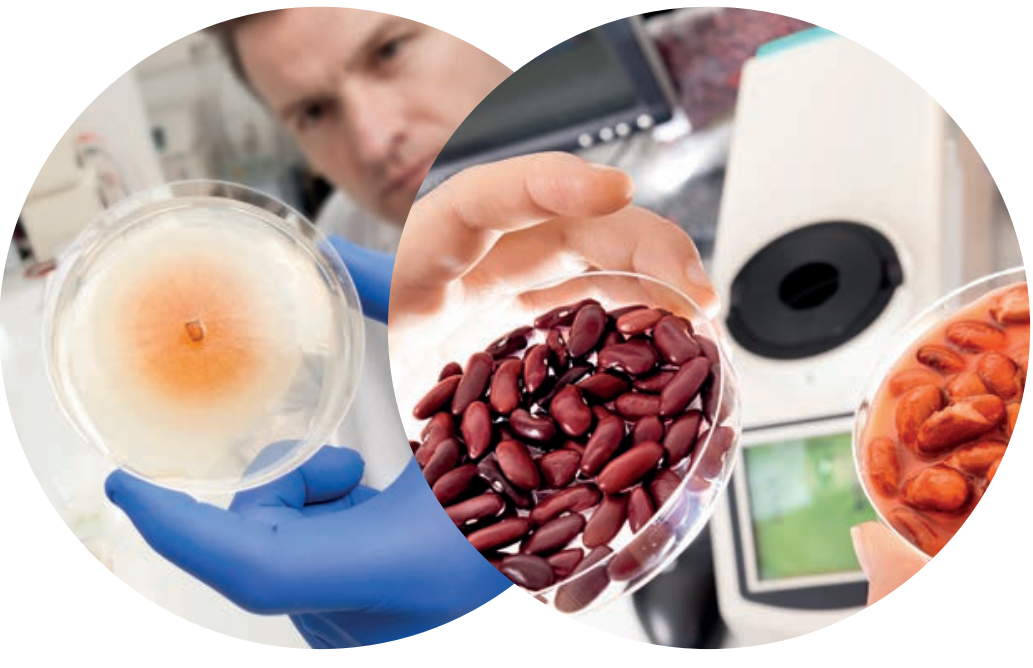

The mission of Wageningen University and Research is "To explore the potential of nature to improve the quality of life". Under the banner Wageningen University \& Research, Wageningen University and the specialised research institutes of the Wageningen Research Foundation have joined forces in contributing to finding solutions to important questions in the domain of healthy food and living environment. With its roughly 30 branches, 6,500 employees (5,500 fte) and 12,500 students, Wageningen University \& Research is one of the leading organisations in its domain. The unique Wageningen approach lies in its integrated approach to issues and the collaboration between different disciplines. 